NUREG/CR--5773

TI92 000969

\title{
Selection of Models to \\ Calculate the LLW Source Term
}

Manuscript Completed: July 1991

Date Published: October 1991

\section{DISCLAIMER}

Prepared by

T. M. Sullivan

Brookhaven National Laboratory

Upton, NY 11973

\begin{abstract}
This report was prepared as an account of work sponsored by an agency of the United States Government. Neither the United States Government nor any agency thereof, nor any of their employees, makes any warranty, express or implied, or assumes any legal liability or responsibility for the accuracy, completeness, or usefulness of any information. apparatus, product, or process disclosed, or represents that its use would not infringe privately owned rights. Reference herein to any specific commercial product, process, or service by trade name, trademark, manufacturer, or otherwise does not necessarily constitute or imply its endorsement, recommendation, or favoring by the United States Government or any agency thereof. The views and opinions of authors expressed herein do not necessarily state or reflect those of the United States Government or any agency thereof.
\end{abstract}

Prepared for

Division of Low Level Waste Management and Decommissioning

Office of Nuclear Material Safety and Safeguards

U.S. Nuclear Regulatory Commission

Washington, DC 20555

NRC FIN L1409

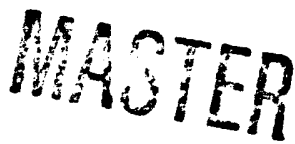




\begin{abstract}
Performance assessment of a LLW disposal facility begins with an estirnation of the rate at which radionuclides migrate out of the facility (i.e., the source term). The focus of this work is to develop a methodology for calculating the source term. In general, the source term is influenced by the radionuclide inventory, the wasteforms and containers used to dispose of the inventory, and the physical processes that lead to release from the facility (fluid flow, container degradation, wasteform leaching, and racionuclide transport). In turn, many of these physical processes are influenced by the design of the disposal facility (e.g., infiltration of water). The complexity of the problem and the absence of appropriate data prevent development of an entirely mechanistic representation of radionuclide release from a disposal facility. Typically, a number of assumptions, based on knowledge of the disposal system, are used to simplify the problem. This document provides a brief overview of disposal practices and reviews existing source term models as background for selecting appropriate models for estimating the source term. The selection rationale and the mathematical details of the models are presented. Finally, guidance is presented for combining the inventory data with appropriate mechanisms describing release from the disposa! facility.
\end{abstract}




\section{TABLE OF CONTENTS}

ABSTRACT $\ldots \ldots \ldots \ldots \ldots \ldots \ldots \ldots \ldots \ldots \ldots \ldots \ldots \ldots$ iii LIST OF TABLES AND FIGURES $\ldots \ldots \ldots \ldots \ldots \ldots \ldots \ldots \ldots$ vii EXECUTIVE SUMMARY $\ldots \ldots \ldots \ldots \ldots \ldots \ldots \ldots \ldots$ ix ACKNOWLEDGEMENTS $\ldots \ldots \ldots \ldots \ldots \ldots \ldots \ldots \ldots \ldots \ldots \ldots \ldots$ xiii

1. INTRODUCTION $\ldots \ldots \ldots \ldots \ldots \ldots \ldots \ldots \ldots \ldots \ldots \ldots \ldots \ldots \ldots$

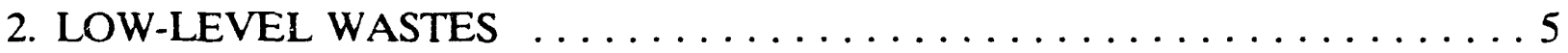

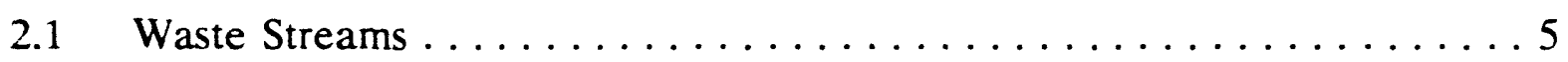

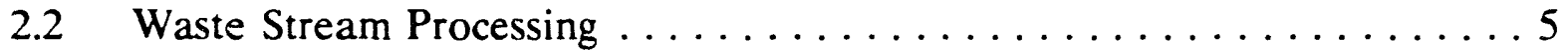

2.3 Waste Containers ......................... 5

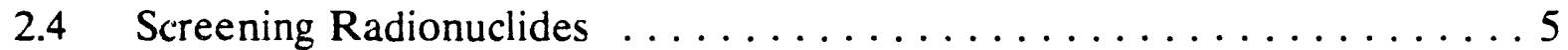

2.5 Disposal Practices . . . . . . . . . . . . . . . . . . 6

3. REVIEW OF PREVIOUS SOURCE TERM

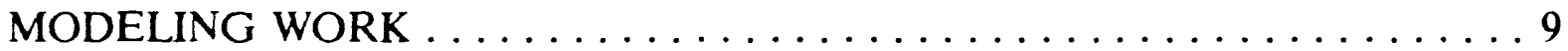

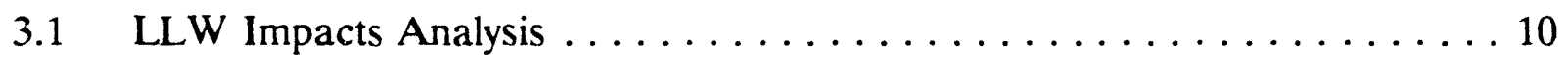

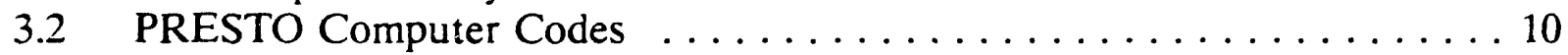

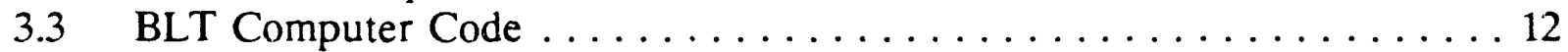

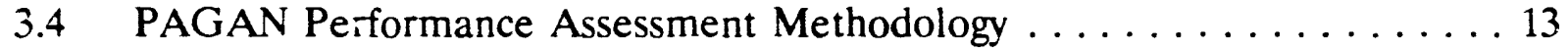

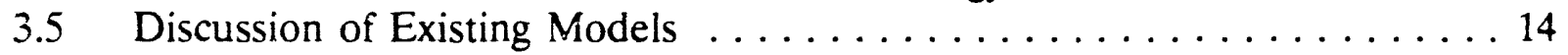

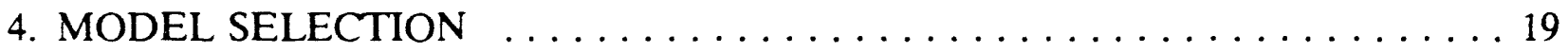

4.1 Source Term Modeling Framework $\ldots \ldots \ldots \ldots \ldots \ldots \ldots \ldots$

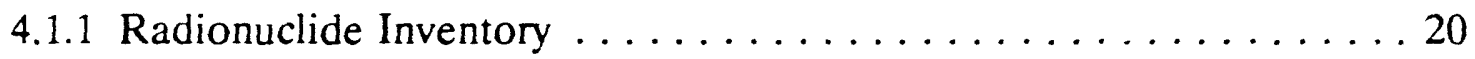

4.1 .2 Water Flow . . . . . . . . . . . . . . . . . . . . . . 21

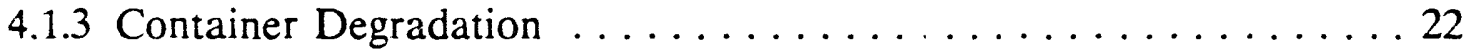

General Failure .....................23

Localized Failure ........................ 24

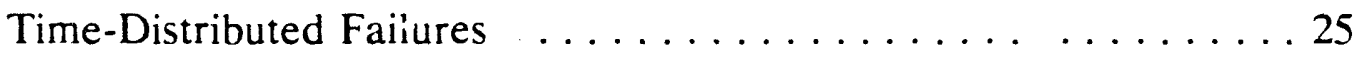


TABLE OF CONTENTS (cont.)

Page

4.1.4 Wasteform Leaching . . . . . . . . . . . . . . . . 25

Release from Partially Failed Containers . . . . . . . . . . . 27

4.1.5 Radionuclide Transport ...................... 29

$4.2 \quad$ Probabilistic Modeling $\ldots \ldots \ldots \ldots \ldots \ldots \ldots \ldots \ldots \ldots \ldots \ldots \ldots \ldots$

5. PROCEDURE FOR CALCULATING RELEASES FROM A

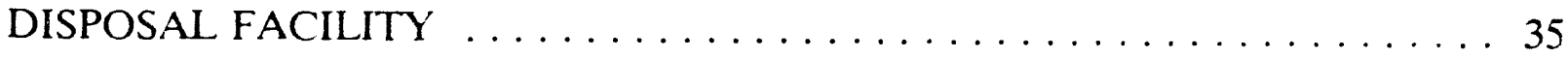

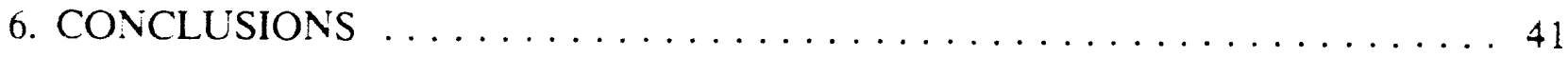

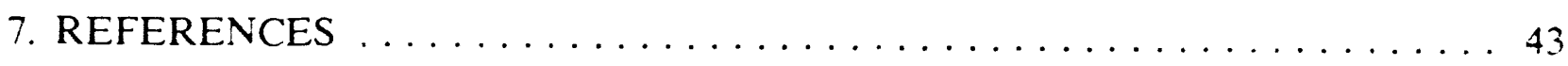

Appendix A: MATHEMATICAL DESCRIPTION OF THE MODELS

SELECTED FOR THE SOURCE TERM ANALYSIS $\ldots \ldots \ldots$ A-1 


\section{LIST OF TABLES AND FIGURES}

$\underline{\text { Page }}$

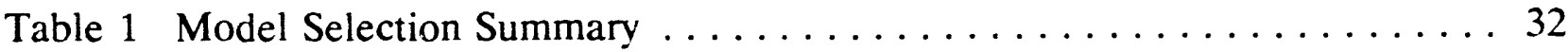

Figure 1 Schematic diagram of a LLW Disposal Unit $\ldots \ldots \ldots \ldots \ldots \ldots$

Figure 2 Schematic representation of the four processes that influence release of radioactivity from a LLW disposal

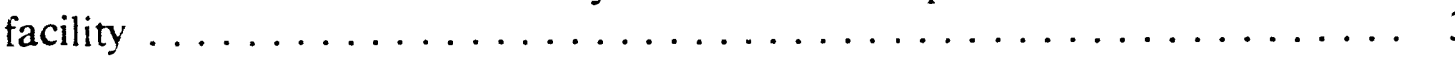

Figure 3 Diffusional fractional release rate from a cylinder $(\mathrm{r}=28 \mathrm{~cm}, \mathrm{~h}=85 \mathrm{~cm})$ as a function of time and diffusion

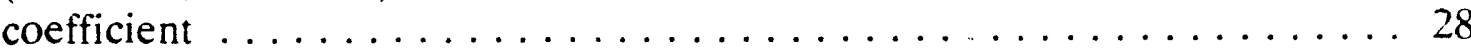

Figure 4 Schematic representation of the mixing cell cascade approach.

(a) a single mixing cell, (b) multiple mixing cells $\ldots \ldots \ldots \ldots \ldots \ldots 30$

Figure 5 Flowchart of the procedure used to take waste stream/wasteform/ container inventory data and define the necessary input parameters to estimate the release rate from a disposal facility

Figure 6 Pu-241 radioactive decay chain. The maximum activity of the daughter species can be used in estimating an adjusted inventory of the daughters without explicitly considering decay of the parent. [From Kozak, 1990] . . . . . . . . . . . . . . . . . . . 39 


\section{EXECUTIVE SUMMARY}

The U.S. Nuclear Regulatory Commission (NRC) Regulation 10 CFR part 61, "Licensing Requirements for Land Disposal of Radioactive Waste," requires that after disposal of lowlevel wastes (LLW) there is reasonable assurance that the general public will not receive annual off-site doses in excess of 25 millirems to the whole body, 75 millirems to the thyroid, and 25 millirems to any other organ. The facility must also be designed to provide for protection of inadvertent intruders. The demonstration that these regulatory limits are not exceeded requires the quantitative assessment of the potential impact of all LLW disposal facilities on the surrounding environment.

Evaluation of the radiological impacts of LLW disposal is accomplished through a performance assessment which includes estimates of the following processes for each radionuclide: (a) the rate of release from the disposal unit (i.e., the source term); (b) the transport from the disposal unit to the accessible environment; and (c) the conversion of the radionuclide concentration at the receptor site into an equivalent dose.

The objective of this project is to provide computer models that estimate the radionuclide release rate from the disposal facility. These models should be modular in structure to allow further refinements. should be capable of running quickly on a desktop computer system, and should be flexible enough to handle the wide variety of situations encountered in LLW disposal.

In general, the source term is influenced by the radionuclide inventory and its origin (i.e., waste stream), the wasteforms and containers used to dispose of the inventory, and the physical processes that lead to release from the facility (fluid flow, container degradation, wasteform leaching, and radionuclide transport).

The complexity of the problem and the absence of appropriate data prevent development of an entirely mechanistic representation of radionuclide release from a disposal facility. Typically, a number of assumptions, based on knowledge of the disposal system, are used to simplify the problem. This document provides a brief overview of current disposal practices as a background for the modeling assumptions. This review discusses the basic characteristics of the waste, wasteforms, waste containers, and disposal unit.

Several computer codes that are capable of calculating the source term exist. A few of these codes (the NRC Updated Impacts Analysis, the EPA's PRESTO codes, the PAGAN code, and the BLT code) have been reviewed in terms of the requirements of this project. Based on this review it was determined that none of the existing codes filled all of the program objectives. The codes tended to be either too restrictive in modeling releases from the wasteform or would require extensive input and computational time. Thus, it was decided to develop a new code based on models from existing codes. 
The strategy for modeling radionuclide release from the disposal trench, the rationale for model selection, and the preliminary model selection for the four major processes (fluid flow, container degradation, wasteform leaching, and radionuclide transport) are presented. Modeling release of gaseous radionuclides is also discussed. A summary of the models selected for the source term analysis is found in Table ES-1.

The proposed source term model improves upon existing models in that more flexibility is allowed in order to model the various waste stream/wasteform/container systems while still retaining relatively simple models that do not require extensive computer time or provide an undue burden on the code user in terms of input requirements. Using the newly developed source term model, it will be possible to specify different release models and parameters for each waste stream/wasteform combination. 


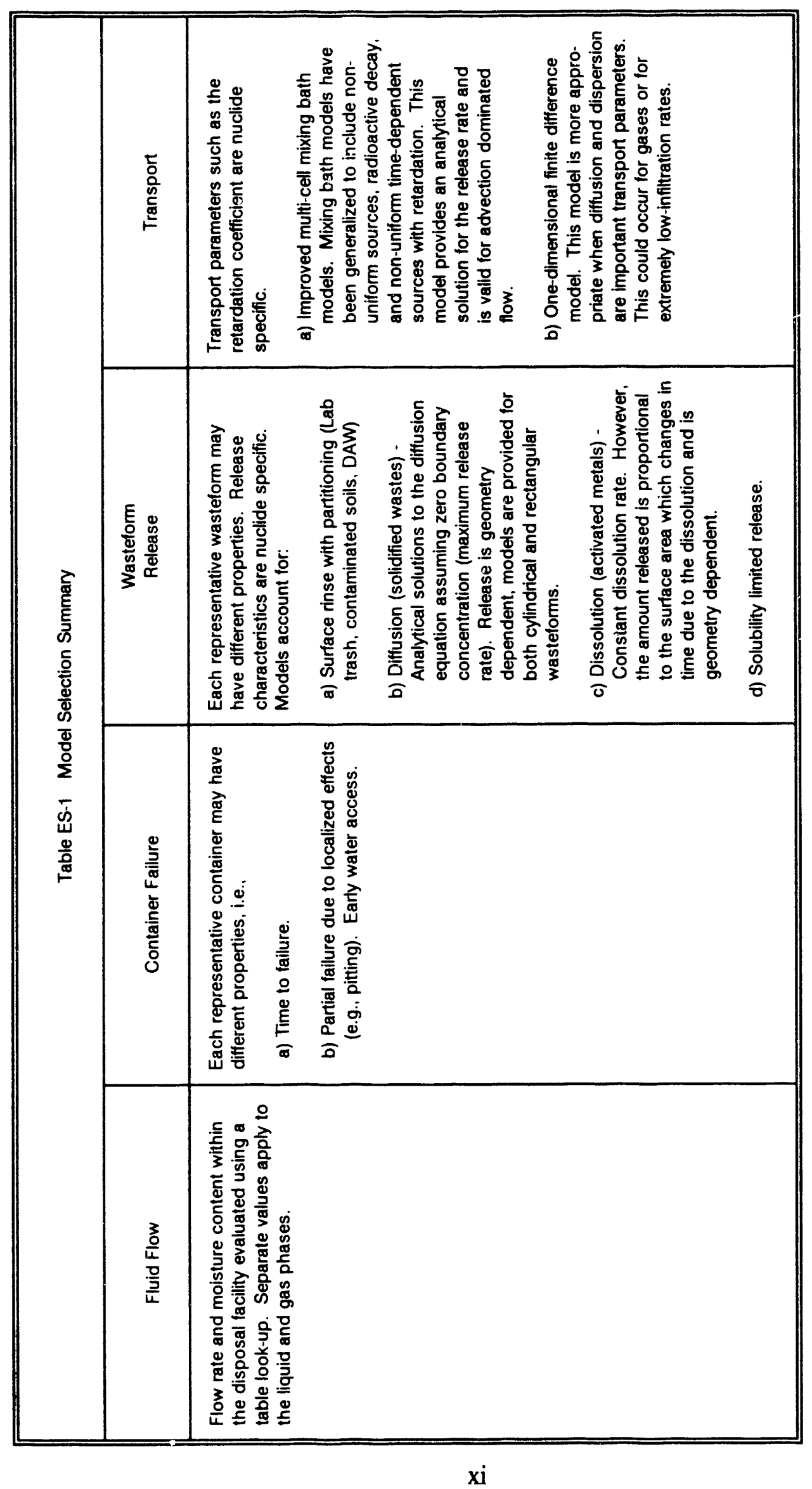




\section{ACKNOWLEDGEMENTS}

The author thanks Mr. M. Thaggard of the U.S. Nuclear Regulatory Commission, Office of Nuclear Material Safety and Safeguards, Dr. M. Kozak of Sandia National Laboratories, and Dr. C. Pescatore of Brookhaven National Laboratory for their critical review and useful suggestions to improve this report. The author also gratefully acknowledges the skillful preparation of this report by Ms. A. Lopez of Brookhaven National Laboratory. 


\section{INTRODUCTION}

The U.S. Nuclear Regulatory Commission (NRC) regulation 10 CFR part ó1, "Licensing Requirements for Land Disposal of Radioactive Waste" [FR, 1982], requires that after disposal of low-level wastes (LLW) there is reasonable assurance that the general public will not receive off-site doses in excess of 25 millirems to the whole body, 75 millirems to the thyroid, and 25 millirems to any other organ. The facility must also be so designed to provide for protection of inadvertent intruders. This requires the quantitative assessment of the potential impacts of a LLW disposal facility on the surrounding environment. In particular, estimation of the dose to the maximally exposed individual is required.

Estimation of the dose to man is accomplished through a performance assessment. A proposed strategy for conducting such an assessment has been presented by the NRC [Starmer, 1988]. In this strategy, performance assessments are conducted through combining a series of separate calculations. These include estimating for each radionuclide: (a) the rate of release from a disposal unit (i.e., the source term); (b) the transport from the disposal unit to the accessible environment; and, (c) the conversion of the radionuclide concentration at the receptor site into an equivalent dose. Examples of this approach can be found in the reports produced for the NRC by the staff at Sandia National Laboratories [Kozak, 1989; Kozak, 1990; Chu, 1991].

The objective of this project is to orovide computer models that estimate the radionuclide release rate from the disposal facility. The disposal facility may be composed of several disposal units. A single disposal unit is schematically depicted in Fig. 1. It typically contains a cover to divert water away from the waste containing region. An engineered barrier to further isolate the wastes (for trench disposal there is no engineered barrier). Wasteforms are placed in containers within the disposal unit.

Before providing the models, the physical and chemical processes that influence the source term must be ascertained. The basic processes that influence release from a disposal unit have been discussed previously [Sullivan, 1988] and the problem has been divided into four processes [Fig. 2]:

a) water infiltration, which is a function of the disposal unit design and local environment (amount of rainfall, evapotranspiration, etc.);

b) container degradation, which is a function of the container material and design, and the local environment (corrosivity of the soil water, etc.);

c) wasteform leaching, which is a function of the wasteform and the solute contacting the wasteform; and 


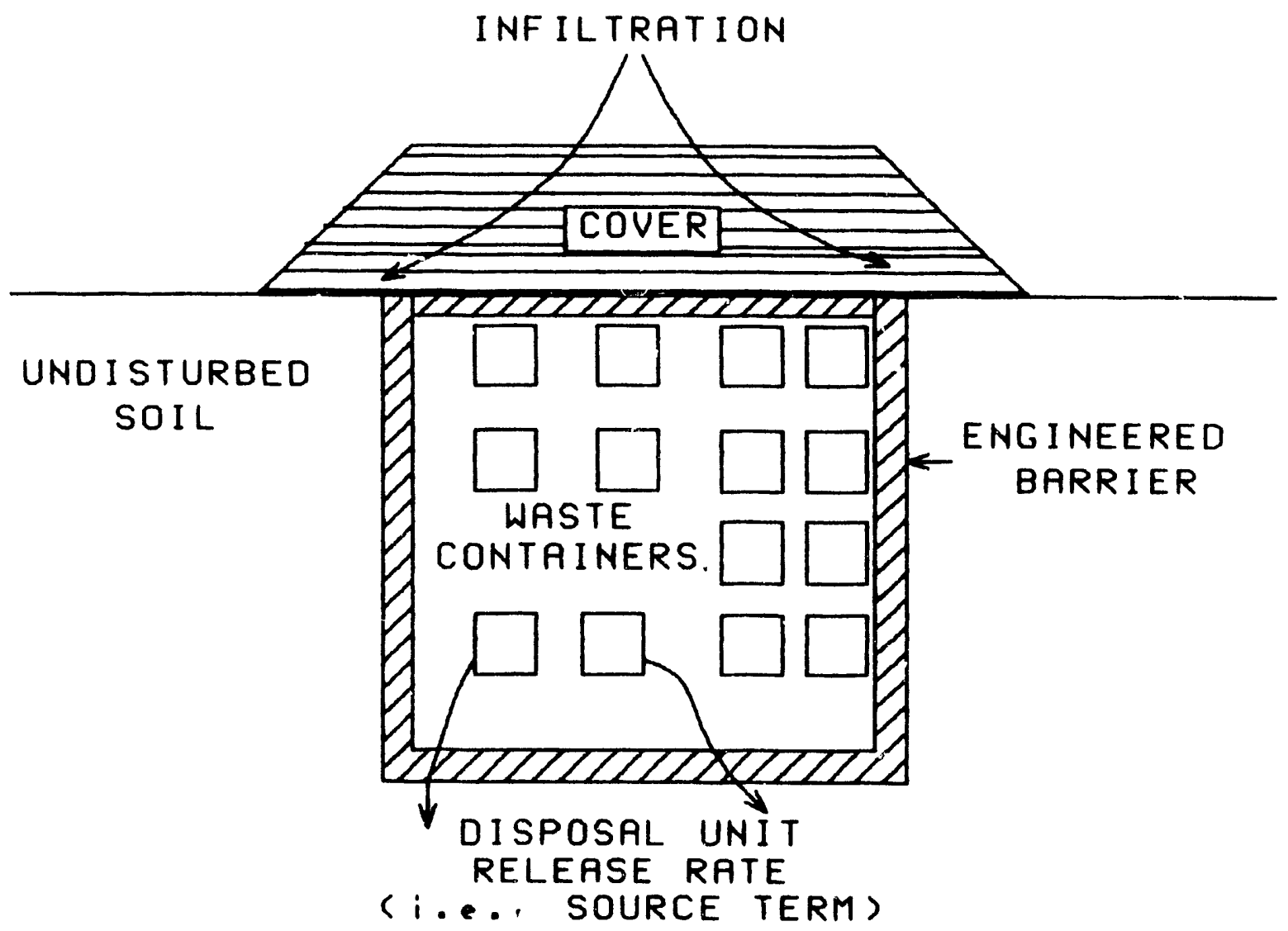

Figure 1 Schematic diagram of a LLW Disposal Unit. 


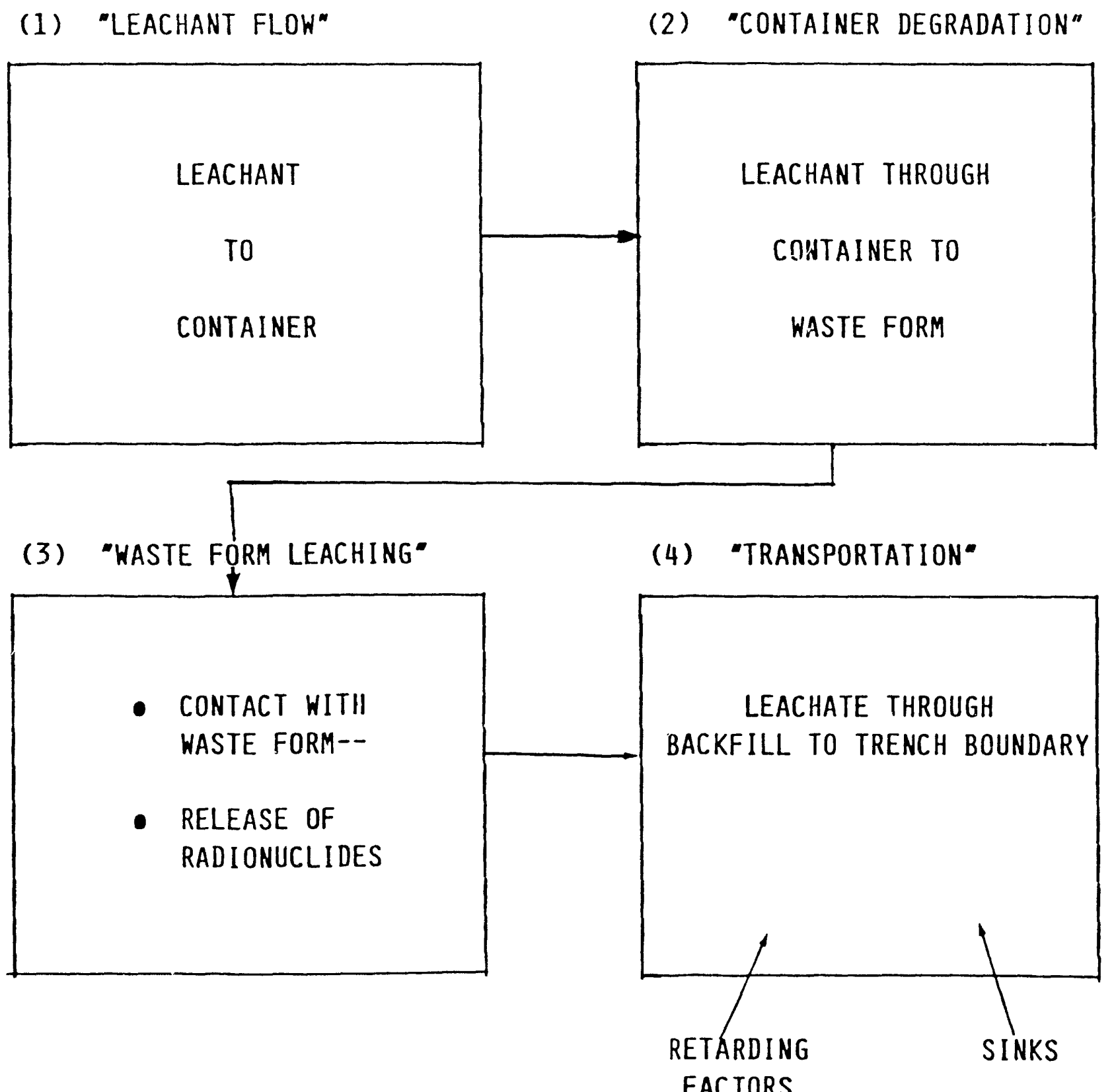

Figure 2 Schematic representation of the four processes that influence release of radioactivity from a LLW disposal facility. 
d) transport, which is a function of the contacting medium, infiltration velocity, and local chemistry.

Requirements of the computer code based on the four process models listed above are that it is: a) modular in structure, to allow further improvements, b) compact enough in size to permit solution on a desktop computer (i.e., a 286 based machine), and c) flexible enough to represent the wide range of situations encountered in LLW disposal.

Prior to model selection, the basic characteristics of the waste, wasteforms, waste containers, and disposal unit must be determined. Chapter 2 presents a brief description of these characteristics and discusses their impact on the model selection.

Chapier 3 reviews previous scurce term models as background for this project. Models considered for review include the Updated Impacts Analysis methodolcgy [Otzunali, 1986], the PRESTO compluter codes [POP, 1987; CPG, 1987] used by EPA in their evaluation of LLW disposal risks, the BLT computer code [Sullivan, 1989], and the PAGAN performance assessment code [Chu, 1991].

Chapter 4 discusses the modeling strategy and the preliminary model selection for the four major processes (water flu , container degradation, wasteform leaching, and radionuclide transport). Modeling the release of gaseous radionuclides is also discussed.

Chapter 5 describes methods for taking the inventory (manifest) data and translating them into the form required for performance assessment.

Chapter 6 summarizes the work presenter. 


\section{LOW-LEVEL WASTES CHARACTERISTICS}

\subsection{Waste Streams}

Commercial low-level wastes are generated at a variety of sources including nuclear reactors, fuel fabrication plants, hospitals and health care facilities, isotope production plants, research facilities, etc. Each of these sources typically produces wastes with different characteristics. LLW includes such diverse substances as activated metals, ion exchange resin beads, filters, sludges, animal carcasses, evaporator concentrates, and contaminated lab trash made of paper, cloth, or plastics.

\subsection{Waste stream processing}

The Updated Impacts Analysis [Otzunali, 1986] describes 148 different LLW waste streams. Each of these waste streams may be processed differently in creating a wasteform. Wet waste streams such as ion exchange resins, cartridge filters, and filter media are typically dewatered and placed in high integrity containers or solidified in cement, bitumen, or a polymeric material. Evaporator concentrates are always solidified. Dry waste streams such as lab trash may be disposed of directly or compacted. Activated metals may be solidified in cement to minimize voids and reduce radiation fields.

\subsection{Waste Containers}

The wasteform is placed into a container. Class A wastes are most often placed in carbon steel drums or boxes. High integrity containers (HIC's) used for class B and C wastes, are currently made from corrosior resistant metal alloys, reinforced concrete, high density polyethylene (HDPE), or polymer-coated metals. HIC containers may include liners of polyethylene.

\subsection{Screening Radionuclides}

Compilations of the radionuclides present in LLW have been generated [Otzunali, 1981; Otzunali, 1986; DOE, 1987; DOE, 1990; Roles, 1990]. These lists indicate over 200 radionuclides may be disposed of in a LLW facility. In addition, consideration is needed to account for the fact that some radionuclides may be produced due to decay of other radionuclides. For example, Am-241 is produced through the decay of Pu-241. Methods for treating this phenomena are discussed in Chapter 5.

To avoid calculating the fate of each radionuclide, a screening methodology must be used to ascertain which are the most important in terms of eventual dose to man. Such a methodology has been proposed [Bowerman, 1990a] and ranks the radionuclides based on inventory, half-life, toxicity index, and environmental mobility. Other screening techniques, based on inventory, half-life, and mobility have also been proposed [Looney, 1987; EPA, 1988]. 
The potential number of different waste stream/wasteform/waste container systems disposed of at a LLW facility runs into the thousands. To avoid the need to treat each separate case individually, a method is also needed to group the wasteform/waste container systems based on the most likely release mechanisms. Bowerman [Bowerman, 1990b] has proposed such a methodology. In this approach, the radionuclides in the various wastes streams are grouped into three broad categories: ionic, chemically bound, or gaseous. These categories are subdivided based on the type of wasteform (cement, dry compacted, polymeric, etc.) and the type of container (carbon steel drums, metal high integrity containers, concrete containers, etc.).

Due to the wide variety of radionuclides and waste stream/wasteform/waste container systems used in LLW, simplifying assumptions must be made to aliow efficient calculation of the source term. The radionuclide screening and wasteform/waste container grouping schemes developec by Bowerman provides a first step in linking expected wastes with the mechanisms leading to release.

\subsection{Disposal Practices}

Presently, there are six commercial low-level waste disposal sites. Three are currently in operation and are located at Barnwell, South Carolina; Richland, Washington; and Beatty, Nevada. The other three sites are located at Sheffield, Illinois; Maxey Flats, Kentucky; and West Valley, New York.

All sites were opened prior to issuance of 10CFR Part 61 and used similar disposal techniques. Open trenches constitute the primary burial mode with the excavated material being used as the intermediate and final cover. Wastes are placed in the trench on an asreceived basis. There is no attempt to segregate similar waste streams within a trench. In some cases, the containers are stacked on top of each other. In others, the wastes are placed in a random orientation within the trench. The size of the trenches and the techniques used to cover the waste vary from site to site due to differences in local conditions (i.e., climate and depth to the water table). Backfilling of soil around the wasteform may be done on a daily to a weekly basis as needed for radiation shielding and cover from rain. The size of the disposal site is typically a few thousand acres.

At the operating sites, current practices follow the regulations specified in 10CFR Part 61. That is, stabilization is required for all Class $B$ and $C$ wastes to minimize subsidence and the resulting increase in water flow. The unstabilized Class $A$ wastes are segregated from Class $B$ and $C$ wastes. Class $A$ stabilized wastes may be placed with either the Class $\mathrm{B}$ and $\mathrm{C}$ stabilized wastes or the Class $\mathrm{A}$ unstabilized wastes. Class $\mathrm{C}$ wastes have a minimum of a $5 \mathrm{~m}$ thick soil cover as an intruder protection barrier.

The trend in LLW disposal is towards more robust disposal technologies. These include above and below grade vaults, earth-mounded concrete bunkers, augered holes, and mined cavities [Bennett, 1984]. Although there are no restrictions on the materials to be used for 
these technologies, the materials mosi commonly recommended are concretes, grouts, and masonry products. The purpose for using these more elaborate and more expensive techniques is to reduce water infiltration to the wastes. Many of the state compacts are proposing to use concrete vaults for the disposal of the waste.

One objective of this program is to develop models that are flexible enough to handle these different disposal concepts with only minor modifications (e.g., use of different data). This is discussed further in Chapter 4. 


\section{REVIEW OF PREVIOUS SOURCE TERM RELEASE MODELING WORK}

There are several models that predict the release of radionuclides in solution from a LLW disposal trench. Typically, these source term models are embedded in computer programs which predict the health hazards associated with LLW disposal Examples of some of the more widely used and/or detailed methods of predicting release can be found in the NRC's LLW Impacts Analysis [Otzunali, 1986], EPA's PRESTO family of computer codes [POP, 1987; CPG, 1987], the BLT source term code developed for NRC [Sullivan, 1989], the performance assessment methodology developed for NRC [Kozak, 1989a; Chu, 1991], and the stream tube model NEFTRAN [Longsine, 1987] which has the ability to model decay chains.

Although computer codes based on the strearn tube approach such as NEFTRAN offer promise for calculating the flux of radionuclides irom the disposal facility, they are limited in their ability to calculate concentrations. Calculating ground-water concentrations requires introducing an arbitrary dilution volume. Therefore, as recommended in the performance assessment methodology development program performed by Sandia for the NRC [Kozak, 1990], stream tube methodologies were not considered further in this program.

The source term models previously listed are reviewed in the following sections in terms of their applicability to the current project. Although many other models exist, it is felt that these models cover the range of conditions expected in a LLW facility. A review of some of the other models and codes can be found in the reports prepared by the staff of Sandia National Laboratories during their performance assessment methodology program [Kozak, 1989; 1989a; 1990].

This brief review covers only the aspects of these codes that influence the predicted releases from the disposal unit. That is, the waste stream/wasteform/container inventory data, and the processes of water flow, container degradation, wasteform leaching, and radionuclide transport. This review is meant to provide a broad overview of the capabilities of each of the source term models. It is not meant to provide a detailed analysis of the models strengths and weaknesses, however, these issues will be addressed in terms of their relevance for selecting models for use in obtaining a source term for performance assessment.

A major exception to the completeness of the models reviewed involves consideration of gaseous release. Gaseous release could arise due to radioactive decay (radon), release of nuclides disposed of as a gas (krypton, tritium), or biotransformation into a gaseous compound (carbon-14, tritium). One estimate performed for the EPA stated that $2 / 3$ of the ${ }^{14} \mathrm{C}$ located in a shallow land disposal facility would be released to the atmosphere as a gas [Gruhlke, 1986]. Currently, adequate models for predicting gaseous release do not exist. 


\subsection{LLW Impacts Analysis}

The LLW Impacts Analysis methodology was used to support NRC analyses of potential releases of radionuclides due to near surface disposal. The code was characterized as being most useful for the comparison of alternative disposal scenarios and not as a method of obtaining absolute predictions [Otzunali, 1986].

The models for release and transport of radionuclides use simple empirical equations comprised of a number of factors that account for site design, waste package, and wasteform. In terms of the four processes identified as controlling release from the disposal system:

a) Water flow within a disposal unit is treated as a single-valued input variable for the flow rate that is time-independent.

b) Container breach is modeled assuming that all containers fail at a user specified time.

c) Wasteform release is modeled as a product of factors that account for the delay time before the containers fail, site design, and wasteform. Release is independent of the radionuclide.

d) Transport is not considered within the disposal unit. Underneath the disposal unit, radionuclide migration is driven by advection (diffusion and dispersion are ignored) and a radionuclide specific retardation coefficient.

The inventory analysis is the most detailed description of radionuclides and waste streams used in any of the source term computer codes. One hundred radionuclides and one-hundred and forty-eight waste streams were considered. However, in calculating release, the models did not take full advantage of this detail as many of the waste streams were lumped together and given similar release characteristics. The inventory data were based on estimates available at the time and do not necessarily reflect current inventories.

\subsection{PRESTO Computer Codes}

The PRESTO family of computer codes has been used extensively by the Environmental Protection Agency, EPA, in modeling the potential impacts of various LLW disposal options [POP, 1987; CPG, 1987]. The codes address groundwater, surface water, food chain and atmospheric pathways. Groundwater pathways include release to downstream wells, rivers and streams. Release to surface waters can also arise due to overflow of the trench (i.e., the bathtub effect). Atmospheric releases are modeled for spills during operation and resuspension of particulates contaminated with radionuclides that overflow a trench. They do not model gaseous release of radionuclides, such as ${ }^{3} \mathrm{H}$, and ${ }^{14} \mathrm{C}$, from the trench. 
Water flow through a disposal unit is calculated based on the fraction of the cap that is intact. The volume infiltrating the intact portion of the cap is calculated from a detailed model which includes evapotranspiration and surface run-off. The model requires daily temperatures and rainfall as well as the hydraulic properties of the cap and underlying disposal unit. The damaged portion of the cap is assumed to provide no barrier to infiltration and the rate of water flow through this portion of the cap is equal to the incident rainfall. Total water flow through the cap is the sum of the intact and failed volumetric flow rates. The time-dependent fraction of the trench cap that has failed is supplied through tabular input.

Container degradation is modeled assuming that the fraction of container failures increases linearly with time until all containers have failed. The time of the first and last container failure are controlled through input.

Wasteform leaching models in the PRESTO-CPG code consider two major classes of waste: solidified and absorbing materials. Five different wasteforms are modeled: absorbing wastes, trash, solidified wastes, activated metals, and incinerated/solidified wastes. The PRESTO-CPG code considers three different solidified wasteforms, (activated metals, solidified wastes, and incinerated/solidified wastes) each with a different release rate. Trash wastes are considered to be a mixture of solidified and absorbing wastes. That is, a certain fraction of the trash wastes release similar to solidified wastes and the remainder release similar to absorbing wastes.

Leach rates are computed on a yearly basis in a two step process. For solidified wastes a radionuclide-independent constant leach rate is obtained from input. Recommended values for the leach rate are dependent on the environment and wasteform. The calculated inventory leached out in one year from the solidified wastes is added to the inventory of the absorbing materials. This inventory is partitioned between the solution and the wasteform using a radionuclide-specific partition coefficient. The solute concentration is further modified by multiplying it by the fractional contact time, that is, the fraction of the year during which water contacts the waste. The contact time can be set to one through input.

The yearly release from the disposal unit is the product of the solute concentration, the fractional contact time, the fraction of failed containers, and the volumetric flow rate through the unit. Thus, the disposal unit is treated as a mixing bath with uniform concentration. There is no attempt to model diffusion/dispersion within the trench.

The inventory is estimated from 25 waste streams and 40 radionuclides. The waste streams are a combination of the 36 waste streams used in the Impacts Analysis conducted for the NRC in 1981. Each waste stream is assigned to one of the five categories of wasteforms. Thus, in practice, several waste streams are grouped into a single wasteform with single release characteristics. 


\subsection{BLT Computer Code}

The BLT computer code was developed for the NRC as a means of predicting release rates to the groundwater from shallow land disposal facilities. Unlike the pievious two models, it is not a dose to man code. The BLT code does not consider atmospheric releases or releases to the surface waters due to overflow of the trench.

The BLT code provides the most detailed models for container degradation and for leaching and transport processes within the disposal facility. The disposal facility is modeled in two dimensions using finite elements. Each of the finite elements can be used to simulate a different wasteform/container; i.e., each element may be assigned different inventory, container parameters, and leaching characteristics.

BLT's companion code FEMWATER calculates the flow velocities and moisture content within the disposal facility in two dimensions. This allows simulation of the effect of trench caps, multi-layered soils and disposal geometry on flow.

Container degradation is calculated using one of two models. For carbon steels which are known to undergo extensive pitting, a pitting corrosion model based on the extensive soil corrosion data base [Romanoff, 1957] collected by the National Bureau of Standards, NBS, (currently named the National Institute of Standards and Technology), is recommended. The pitting model allows for partial container failure and subsequent water accessibility to the wasteform. For stainless steel, a uniform corrosion model is recommended. This model predicts total failure of the container when the corrosion allowance is exceeded. A range of corrosion rates obtained from NBS data is supplied with the code. For other containers (e.g., HDPE HIC's, Ferralium HIC's, etc.) the uniform corrosion model is recommended. However, the data base is insufficient to provide recommended values.

Release from the wasteform is described by three major release mechanisms:

a) surface wash-off with partitioning,

b) diffusion, and

c) dissolution.

The surface wash-off model assumes that radionuclides are available for immediate release upon contact with water subject to partitioning between the wasteform and the

solution. Release is further limited so that solution concentrations do not exceed solubility constraints.

The diffusion model through the wasteform is appropriate for many solidified wastes. Several different analytical models are incorporated into the code allowing, the simulation of semi-infinite or finite plane geometry or finite cyiindrical geometry. The analytical 
solutions are conservative in cases where the concentration outside the wasteform builds up to levels that influence the release from the wasteform (for example, solubility limited release or slow transport away from the wasteform). In such cases, the wasteform can also be modeled using the method of finite differences and the contacting solution is treated as a well-stirred fluid (i.e., mixing bath). The mixing bath model has recently been incorporated into BLT [Sullivan, 1991].

The dissolution model is most appropriate for activated metals. It assumes that release is controlled by dissolution of the wasteform and that the release rate is constant at all times. However, the release rate is decreased in situations when the solubility limit is approached and is zero when the solubility limit is reached.

The mass fraction of waste that is controlled by each of the three release mechanisms is specified by the user for each waste containing element. This allows the homogenization of wasteforms with different release characteristics within a single finite element.

Transport within the trench is calculated through solution of the advection/dispersion equation in two dimensions with retardation and radioactive decay. The code calculates the flux out of the trench at each computational point along the edge of the trench. These can be summed to obtain the total release from the trench or they can be used as input to doseto-man codes.

In terms of inventory, the BLT code is not as prescriptive as the Impacts Analysis or the PRESTO codes. The BLT code assumes that the inventory is known, it does not have a data base containing waste stream information. Rather, BLT requires that the code user specify the fraction of the inventory that is released according to either one of the three release mechanisms.

\subsection{PAGAN Performance Assessment Methodology}

Staff at Sandia National Laboratories have developed a performance assessment methodology for the NRC [Kozak, 1990:, Chu, 1991]. This methodology recommends the use of several codes to predict the dose to man. In terms of release from the disposal facility, the BLT code was recommended to estimate release for complicated situations which require a high level of detail. However, due to the complexity of the model and input requirements, simpler models were recommended to perform the majority of performance assessment analyses. These models are incorporated into the PAGAN (Performance Assessment Groundwater Analysis of low-level Nuclear wáite) code package developed by Sandia to estimate dose to man due to LLW disposal.

In the PAGAN system water flow is assumed to be known and is treated as an input variable. It is recognized that accurate prediction of water flow in the disposal facility is a difficult task and requires simulation in at least two-spatial dimensions [Kozak, 1990]. Therefore, Sandia staff recommends that water flow be estimated by the computer code 
VAM2D. After VAM2D obtains the water velocities, Sandia recommends that the average velocity in the trench be determined and input into the source term models in PAGAN. This velocity is assumed constant for the duration of the simulation. If the water velocity is predicted to vary significantly throughout the trench, the code VAM2D can also be used to predict the release and transport of radionuclides. The release models incorporated into VAM2D assume constant release rates or partition coefficient limited release. Similar release models are applied within the PAGAN code and will be discussed later.

Container degradation, in PAGAN, is modeled as a delay time until water accesses the wasteform. All containers fail at the same time. After failure they provide no barrier to radionuclide release.

Wasteform leaching models consider two classes of waste: "stabilized" and "unstabilized". After selection of the waste class, the trench is homogenized and all wastes are given the same release characteristics. Unstabilized wastes are modeled assuming that once water accesses the waste, release is instantaneous and controlled by a nuclidedependent partition coefficient between the waste and water. Stabilized wastes are modeled using a constant release rate corrected for radioactive decay. The rate depends on the wasteform dimensions and the effective diffusion coefficient. This release model can also be used for solubility limited release.

Transport of radionuclides within the disposal facility is assumed to be vertically downward and controlled by advection. The facility is modeled as a series of uniform mixing cells. A mass balance is performed on each mixing cell accounting for the mass released from the wasteform, the mass entering from the previous mixing cell, and the mass leaving the current mixing cell. If the sorption coefficient of a radionuclide has been satisfactorily estimated, this effect can be included in the transport through the facility by using a water velocity reduced by the retardation coefficient.

The inventory of the wasteform is assumed to be known and is treated as an input variable.

\subsection{Discussion of Existing Models}

The source term model developed in this program will have the following characteristics:

a) the ability to model the range of radionuclides encountered in LLW disposal on an individual basis;

b) the ability to model a variety of different waste container/waste form systems in a single simulation; 
c) the ability to examine the influence of the major processes (water flow, container degradation rates, leaching rates, and transport rates) on release from the facility;

d) the ability to execute quickly on a 286-based personal computer; and

e) the ability to interface with the NRC/SANDIA performance assessment codes.

In reviewing the existing source term models, it is recognized that none of the models possess the necessary level of detail in all of the attributes needed to model the release rates from a disposal facility. For example, the Impacts Methodology, the PRESTO codes, and PAGAN do not permit enough flexibility in modeling releases from multiple wasteform/container systems encountered in a LLW facility. The BLT code allows this feature, however, its computational requirements on input and computer time are so large that it makes it impractical to use on the high number of simulations required for performance assessment. The following sections provide specific comments on each of the reviewed models with respect to their strengths and weaknesses. Based on this review, recommendations for selecting models to be used in estimating release from the disposal facility are made and discussed in Chapter 4.

Inventory

To reduce the waste stream/wasteform inventory data to a tractable number of different physical systems, extensive homogenization of the data has been performed. The justification for this step is usually not provided. Nor is there any guidance provided with the models on how to group wasteforms. As part of this program, guidance will be provided on the homogenization of the waste stream/waste form systems.

The Impacts Analysis and PRESTO methodologies have the most detailed inventory descriptions. However, these data are not used to differentiate between release rates from the various waste streams/wasteforms. The PRESTO-CPG code considers 25 waste streams but at most five different release rates (i.e., five different wasteforms). The Impacts Analysis and PAGAN models reduce each simulation to one wasteform. BLT is the most general model as it allows multiple wasteforms and waste containers.

\section{Water flow}

Water flow is recognized as being of primary importance in determining release from the disposal facility. However, unsaturated water flow is numerically difficult to predict. This is especially true for a typical disposal unit that contains several materials with extremely different flow properties. For this reason, the Impacts 
Analysis and PAGAN models use flow rates that are constant. The PRESTO-CPG model allows flow to change linearly in time due to trench cap failure. BLT uses a two-dimensional steady-state flow field calculated by FEMWATER based on the average infiltration of precipitation into the trench cap. A similar approach is used in VAM2D.

If a two-dimensional simulation is performed to estimate infiltration rates, VAM2D which has a more robust iterative solution procedure than FEMWATER is preferred. If a one-dimensional simulation is performed, the value for the flow rate must be selected conservatively for the disturbed site. For example, if a disposal facility were located in a relatively impermeable soil, flow through the disturbed zone, i.e., the disposal facility, would be higher than through the surrounding undisturbed zone. This phenomena has been observed for concrete structures located below grade in impermeable soils in Canada [Bajurny, 1991].

\section{Container Degradation}

Container degradation is typically modeled as a time-to-failure. Little guidance is provided on the choice of an appropriate failure time or on a distribution of failure times.

The BLT code does allow for localized failure due to pitting. This pitting model calculates the amount of area breached per container as a non-linear function of time. The pitting model predicts container breach at a much earlier time than general corrosion. The data base to support the model is limited to carbon steels.

Radionuclide Release

$\checkmark$ ith the exception of BLT, radionuclide release rates from the wasteform are generally assumed to be constant in time or controlled by the local chemistry (partitioning or solubility limits). The PAGAN code permits release rates to be corrected for radioactive decay. The BLT code requires a separate computer simulation for each radionuclide. The other codes have an automated procedure that allows multiple radionuclides to be considered in a single run. However, each radionuclide is modeled independently. The Impacts Analysis and the PAGAN code assume one set of release characteristics for the simulated region of a disposal facility for each computer run, whereas, the BLT code allows each wasteform to have unique release parameters. Further, the Impacts Analysis assumed each radionuclide to be released at the same rate.

The standard leach test ANS16.1 recommends interpreting release data from solidified wasteforms in terms of a diffusion-controlled mechanism [ANS, 1986]. The BLT code does allow diffusion-controlled releases from the wasteform. Such release rates are initially relatively high but then decrease with time. 
Radionuclide ' Transport

The Impacts Analysis makes the conservative assumption that once a radionuclide is released from the wasteform it is released from the disposal unit. The PRESTO-CPG code treats the disposal unit as a single mixing bath in which release is controlled by advection through the bottom of the unit or overflow through the top of the unit. Within the disposal facility, the concentration is assumed uniform. The PAGAN code improves upon this transport model by considering the trench to be a multi-celled mixing bath with the concentration within each mixing bath uniform but different than in other mixing baths. Neither of these models explicitly consider diffusion or dispersion within the disposal facility. However, the mixing-cell cascade model used in PAGAN artificially introduces numerical dispersion within the facility through the mixing process. The amount of dispersion depends on the number of mixing cells and does not correspond to any physically measurable quantity, i.e., there is no direct expression that relates the number of mixing cells to a dispersion coefficient. Although dispersion is numerically introduced within the facility, there is no dispersive flux out of the facility. It is assumed that release from the facility occurs only through advection. The BLT code models transport using numerical solution of the twodimensional advection-dispersion equation.

\section{Modeling the Entire Disposal Facility}

The LLW Impacts Analysis Methodology, PRESTO, and PAGAN simulate one spatial dimension. BLT simulates two. Therefore, to model the three-dimensional disposal unit requires homogenization. Little guidance is provided on how to combine the different wasteform/container systems together.

It may not be practical or even advisable to reduce the disposal unit down to a single 1-D or 2-D slice. In this case, multiple simulations of different regions within the facility could be conducted and their results summed. This assumes that the radionuclide transport equation is linear. This will be the case provided solubility limits do not influence wasteform release and the linear sorption isotherm appropriately describes retardation effects. For example, one analysis could be conducted for the unstabilized Class A section of the facility, another for the stabilized Class $\mathrm{B}$ and $\mathrm{C}$ wastes, and so on.

The PAGAN code allows for multiple simulations within a single computer run. The PLT requires a separate computer run for each simulation. 
Gaseous Release

None of the models revizwed considers gaseous releases from within the trench. The PRFSTO-CPG code dois model airborne release due to resuspension of contaminated particulates on the soil surface due to operational spills or due to water overflow through the top of the trench.

\section{Radionuclide Decay}

None of the codes explicitly considers ingrowth of radionuclides due to decay. The PRESTO-CPG code has used adjusted values of the initial inventory of daughter products to account for decay [EPA, 1988]. However, if they are relatively short-lived, such as $\mathrm{Pb}-210$, they decay quickly and their inventory at later times is underestimated. Although we have not reviewed the VAM2D code, it has the capability of modeling decay chains. 


\section{MODEL SELECTION}

A LLW disposal unit is a complex, heterogeneous collection of wastes/wasteforms/containers, soils, and engineered structures (clay caps, concrete vaults, drains, etc.). Release of radionuclides from this disposal unit is controlled by water flow, access of the water to the wasteform, release of the radionuclide from the wasteform, and transport to the disposal unit boundary. These processes are influenced by the design of the disposal unit, precipitation, hydrology, geochemistry, and wasteform/container characteristics. To model the complete disposal unit, including every waste container individually would require a three dimensional model that considered all of these processes simultaneously. Such a model does not exist today. Even if such a model did exist, its use would requirc extensive computing times and the accuracy of the predictions would be questionable due to limiıations in the data.

Therefore, simplifications from a fully descriptive three-dimensional model are justified. These "simplified" models are a necessary step in developing predictions of the behavior of a LLW disposal site.

The "simplified" models should account for the nost important physical processes and parameters influencing release while retaining as much accuracy as possible. Further, the models should be flexible enough to simulate a wide range of conditions and not be overly conservative. For example, one could require that all of the containers fail instantly upon emplacement. Such a model would be conservi tive but not realistic and it would be inflexible. A better model would be one that allowed a range of container failure times based on the container properties. Such a model would have the flexibility to permit simulation of extremely low probability worst case scenarios, such as instantaneous failure of all containers, as well as more likely scenarios, such as time-distributed container failures.

The source term computer code will be developed in a ganeral manner which allows simulation of the majority of situations expected to occur. However, to account for the possibility of special cases and allow easy modifications of the models within the code to reflect riew and better information, the code structure will be modular.

In the following sections, the framework for modeling the source term from a disposal unit in this project is presented. Within that framework, the models for the processes that influence release are discussed separately. However, the equations describing these processes are not presented in the main body of the report but can be found in Appendix A.

\subsection{Source Term Modeling Framework}

The ultimate objective of this project is to predict the rate of release of radionuclides from a shallow land disposal facility. As discussed earlier, this will be accomplished through use of computer models. These models should be simple enough to allow simulation of a 
large number of cases and flexible enough to allow simulation of a wide range of situations. To achieve this one can use analytical or numerical solution procedures. Analytical solutions often have the advantage of being easier to compute than numerical solutions. Numerical solutions offer the flexibility to model a wider range of conditions. For these reasons both will be retained in the Source Term Model.

This source term model will attempt to achieve a balance between the use of extremely simple but overly conservative assumptions which lead to high predicted release rates and complicated models that include all of the known physical and chemical processes that influence release but require extensive computer time and expertise to define the problem (select the input variables). To strike this balance, assumptions regarding which are the most important physical parameters and the level of detail needed to calculate these parameters are required. Once these assumptions are made it is incumbent on the code user to justify the choices for input data. For wxample, the PAGAN code assumes a constant flow rate through the disposal unit. The code user must supply and justify the choice for that flow rate. Justification can be achieved through use of more sophisticated computer codes that perform a much more detailed calculation to determine the important parameter (e.g. water flow calculated using a two-dimensional computer code such as VAM2D as recommended for PAGAN users) or through expert judgement. In either case documentation of the basis for the use of an input variable should be supplied with the results of any simulation. The potential for misusing the simple models through improper choice of input data is large.

\subsubsection{Radionuclide Inventory}

The radionuclide inventory of the disposal facility, as defined by the waste stream/waste form/container systems, is critical in obtaining a best estimate for the source term. This information (i.e., different systems of waste stream/wasteform/container) can be obtained from the shipping manifests that are required for each wasteform. The information from the manifests can be used to generate a list containing the inventory of each radionuclide in each system.

For modeling purposes, it would be ideal if the number of waste stream/wasteform/container systems were limited to a few well characterized (in terms of release rate) systems. However, this is not the case. In practice there are hundreds of different combinations of waste stream, wasteform, and container. Further, for a particular system, different radionuclides may be released at different rates. To avoid the need for collecting information on each of the potential disposal systems, homogenization of the different disposal systems into a manageable number of systems is performed.

The homogenization procedure identifies first the major waste stream/wasteform/container systems in terms of activity. Based on this ranking, the disposal systems are reviewed in terms of release mechanisms. If the release mechanisms and the release rates are believed to be similar, the different disposal systems can be combined into a 
representative syster. The procedure is continued until all of the activity has been accounted for in the representative systems. Work in this area is in progress and further guidance will be provided in a separate report.

\subsubsection{Water Flow}

New disposal facilities will most probably be located above the water table in the unsaturated zone. Infiltration of water into a facility will involve many processes including precipitation, evapotranspiration, and surface run-off. Water flow in the unsaturated zone is difficult to model due to the non-linearity of the unsaturated soil flow properties. This is furthier complicated by the barriers (trench cap, concrete structure, etc.) any disposal facility will have to minimize infiltration into the waste containing region.

It is apparent that a simple model for infiltration does not exist. Currently, there is no acceptable model capable of predicting infiltration into soils in arid sites under all conditions [Gee, 1988]. To calculate flow into a disposal facility would require at least a twodimensional simulation because of the complex flow patterns that will arise due to the presence of different materials with different flow properties (i.e., the trench cap, engineered barriers, waste containers, backfill, etc.). Further, the flow rate will vary with time on a short time scale ( $\mathrm{r}$ urs) due to precipitation events and evapotranspiration and on a long time scale (years) due to changes caused by degradation of the infiltration barrier. To follow the evolution of water flow with time would require an extensive computing expense. Thus, this is not appropriate for the source term model.

In the source term model water infiltration will be calculated as a function of time through tabular input. This flow rate should be the yearly average based on the expected conditions. For advection driven transport it has been shown that the average rate of contaminant transport depends on the average flow rate [Sullivan, 1988a].

The choice of the value for the flow rate should be conservatively chosen or supported by more detailed computer simulations such as VAM2D [Huyakorn, 1989], FEMWATER [Yeh, 1987], TRACR3D [Travis, 1991], etc. If a computer simulation is not performed, an upper bound for the flow rate is the annual precipitation rate. If the evapotranspiration rate is accurately known this could be subtracted from the precipitation rate at humid sites. At arid sites this may lead to large errors in predicted recharge [Gee, 1988]. Alternatively, if the recharge rate through the disposal facility is known due to measurement at the site, this value could be used.

In the actual situation, infiltration may be very low until significant degradation of the trench cap occurs. If one accounts for degradation of the trench cap, this will require additional modeling. At this time, there is no widely accepted model for the degradation of earthen materials or engineered (i.e., concrete) trench caps. This is due in part to the need to predict performance over hundreds of years based on experience and data that have been collected over a period of years. 
However, work is being performed to determine the degradation mechanisms of underground concrete structures. Models based on these studies are under development [Clifton, 1989; Walton, 1990; Shuman, 1991]. If these models are determined to be acceptable, they could be used to estimate the rate of degradation. This information could then be used to calculate water flow through the degraded barrier and into the waste containing region of the disposal facility.

\subsubsection{Container Degradation}

In the early days of LLW disposal waste containers ranged from cardboard and wooden boxes to carbon steel drums and boxes. Since the passage of 10CFR Part 61, cardboard and wooden boxes are no longer used. As of 1988 , carbon steel drums and boxes were widely used to dispose of Class A wastes, the largest volume of wastes. Most Class B and C wastes are disposed of in HIC's but a small fraction have been stabilized in cement and placed in 55 gallon drums [Sullivan, 1989]. Recently, there has been a trend to rely more and more exclusively on HIC's for Class B and C wastes due to their ease of use, lack of need for processing equipment, reduced worker exposure, problems encountered with solidification of some waste streams, and their approval by NRC as a means of demonstrating structural stability.

A waste generator has had a number of different HIC's from which to choose. These include HIC's made from Ferralium 255, from stainless steels, from polymer-impregnated concrete, and from HDPE. A HIC may also have an internal lining to isolate the waste from the external barrier to water flow. The liner materials are typically polyethylene. HIC's should be designed to maintain their structural stability for 300 years as indicated in the NRC technical position on wasteforms [Higginbotham, 1983; Lohaus, 1991]. Structural stability does not imply that the HIC's will remain water tight. In time, water may enter through the passive gas vents required on HIC's or through small cracks and localized failures that may occur.

Currently, it is likely that most waste containers will be metallic. The use of HDPE is suspect due to the potential of long term creep affecting its stability and it is no longer on the NRC-approved list of HIC's. The Richland site received only five HDPE HIC's in 1988 [Sullivan, 1989] and these HIC's were placed in concrete caissons backfilled with soil to ensure stability. The use of polymer-impregnated concrete HIC's is not widespread due to their costs relative to metallic HIC's.

Modeling of metallic corrosion on a mechanistic scale is strongly dependent on the local chemistry and quite complicated. Mechainistic modeling would require detailed knowledge of the chemical species that influence corrosion. This data is not well known in a disposal environment and would be subject to large uncertainties which would lead to uncertainties in the predicted corrosion rates. Therefore, for the source term model, the work required to perform such a calculation is probably not justified. Rather, source term metallic container degradation models will be semi-empirical and rely on the existing corrosion in 
soil data base. If internal corrosion is expected to be important, this can also be included in the einpirical model through increasing the corrosion rate parameters. Two types of failure will be modeled: general failure, and localized failure.

\section{General Failure}

For the source term model it is recommended that general failure be modeled through a user-specified time of failure. In this model, the container prevents water ingress to the waste until failure, at which time the container no longer provides a barrier to water flow. For metallic containers, the time to failure could be estimated as the thickness of the container divided by the time-averaged corrosion rate.

Corrosion rates should be obtained from site specific data whenever possible. When this is not possible, the data base generated by NBS [Romanoff, 1957; Gerhold, 1981] for carbon steels and stainless steels could be used for these materials. There is no data base for the corrosion of Ferralium in soil systems. However, Ferralium, a duplex stainless steel, has shown much superior corrosion performance as compared to 304 and 316 stainless steels in a wide range of environments. If this trend holds for soil systems, use of the NBS data for stainless steels should be conservative.

The NBS studies of carbon steels covered a period of 17 years and 47 different soils [Romanoff, 1957]. Corrosion rates in this study of carbon steels ranged from $8 \times 10^{-4}-2 \times 10^{-2}$ $\mathrm{cm} / \mathrm{yr}$, with the mean value being $5.7 \times 10^{-3} \mathrm{~cm} / \mathrm{yr}$. In the LLW Updated Impacts Analysis [Otzunali, 1986] the recommended value for carbon steel corrosion was $4 \mathrm{mils} / \mathrm{yr}\left(1 \times 10^{-2}\right.$ $\mathrm{cm} / \mathrm{yr})$.

The NBS studies of 304 and 316 stainless steels were conducted over 14 years in 15 soils. Corrosion rates for 304 stainless steel ranged from $1.7 \times 10^{-5}-1.1 \times 10^{-7} \mathrm{~cm} / \mathrm{yr}$, with the mean value being $5 \times 10^{-6} \mathrm{~cm} / \mathrm{yr}$ [Gerhold, 1981]. Corrosion rates for 316 stainless steel ranged from $5.7 \times 10^{-6}-2.8 \times 10^{-8} \mathrm{~cm} / \mathrm{yr}$, with the mean value being $1.3 \times 10^{-6} \mathrm{~cm} / \mathrm{yr}$ [Gerhold, 1981]. Otzunali recommended a value of $0.3 \mathrm{mils} / \mathrm{yr}\left(7.6 \times 10^{-4} \mathrm{~cm} / \mathrm{yr}\right)$ [Otzunali, 1986].

In the soil corrosion experiments, it was noted that corrosion rates typically decreased over time [Romanoff, 1957, Gerhold, 1981]. Provided that there is no change in the degradation mechanism, the experimentally measured decreasing corrosion rate indicates a constant corrosion rate based on short term data is likely to overpredict the total amount of corrosion.

For containers with non-metallic components (HDPE containers, polyethylene lining in metal, concrete caissons, etc.) there are few data on their long term performance. It is recommended that the general failure rate be selected in a conservative manner based on expert judgement. 


\section{Localized Failure}

In contrast to general failure, a small section of a HIC may also lose its ability to prevent water to access the wasteform. If a localized failure occurs, water will contact the wasteform causing the release of radioactivity before the general corrosion allowance is reached. This solute may be released as the localized area increases leading to release earlier than predicted by the general corrosion model or it may be stored within the container causing a large pulse type release when general failure occurs. In either event it may have a significant impact on predicted releases from the disposal facility.

For metallic HIC's localized failure due to pitting and cracking or failure of the passive gas vents may occur.

Localized corrosion due to pitting has been studied for carbon stecls [Mughabghab, 1989 ] and the pitting rate was found to decrease in time and depend on soil properties ( $\mathrm{pH}$, moisture content, degree of aeration). A correlation to describe this process was recommended and takes the form:

$$
A=k t^{\mathrm{n}}
$$

where $\quad \mathrm{A}=$ the failed area;

$\mathrm{k}=$ pitting parameter dependent on the material type and soil $\mathrm{pH}$;

$\mathrm{t}=$ time (years)

$\mathrm{n}=$ pitting parameter $(\mathrm{n}<1)$

In principle, this model could be used for all metallic containers provided the required data was available for estimating the parameters in Eqn. (3.1). However, for stainless steels, the pitting rate was not statistically significant in the 14 year soil corrosion tests [Romanoff, 1957]. Any choice of parameters for these materials would have to be justified as being conservative.

Consideration should also be given to internal corrosion. HIC's may store wastes without the waste undergoing a solidification process. In this case, the wastes may directly contact the lining or in the absence of a lining the container material. Many LLW wastes contain corrosive agents that could possibly lead to penetration via pitting (localized failure). For example, it has been shown that resin beads in contact with stainless steel led to discoloration and pitting in short term tests [Soo, 1990]. 


\section{Time-Distributed Failures}

Within a disposal facility there will be thousands of containers. For each particular class of contairiers (e.g. 55 gallon carbon steel drums, etc.) the time of failure will vary due to minor differences in local chemistry and in the containers themselves. Thus, it may be more appropriate to consider a range of failure times within each class of container.

Time-distributed failures could be modeled through input by parameters that described their expected distributions. This information is not readily available and would have to be estimated through expert judgement. Further, requiring all containers of a particular class to fail simultaneously will provide higher peak doses unless decay prior to failure plays an important role.

Time-distributed failures can be modeled in a crude fashion by specifying different failure times for nominally similar containers through the user-supplied input.

\subsubsection{Wasteform Leaching}

Radionuclide release from the wasteform commences upon container failure. In a LLW facility there will be several different wasteforms, a partial list of which includes: wastes solidified by one of several processes (cement, VES, bitumen); activated metals; compacted lab trash; dewatered resins; liquids contained in an absorbent; and adsorbed gases [Roles, 1990]. As part of this program an evaluation of disposal data is being made to rank these wasteforms based on activity of key radionuclides and volume.

After the disposal data has been analyzed, each of the major categories of wasteforms will be grouped in terms of release mechanism. The work of Bowerman [Bowerman, 1990b] suggested a preliminary grouping scheme based on the state of the radionuclide contained in the wasteform. The three major categories are:
a) ionic or soluble,
b) chemically bonded, or
c) gaseous.

For radionuclides contained in "ionic form" release comes immediately upon contact with water. For surface contaminated wastes release is instantaneous but may be limited by partitioning or solubility effects. For "ionic" radionuclides distributed throughout the wasteform (for example, ion-exchange resin beads solidified in cement) release is initiated upon contact with water; however, the release rate is often controlled by diffusion through the wasteform. 
Chemically-bonded radionuclides require a chemical reaction to convert the radionuclide to a soluble form. For example, activated metals will release radionuclides after corrosion of the metal matrix. Other chemically-bonded wastes could arise from filter media because the radionuclides are typically oxides or other insoluble particulate matter which have been physically entrapped in the waste. If these filter media are solidified, release may be controlled by reaction to make the radionuclide soluble, by diffusion through the wasteform, or by both processes.

Gaseous radionuclides are expected to release quickly after container failure. For adsorbing gases it is expected that release would be controlled by a partitioning factor. Gases can also be formed by biodegradation, for example, tritiated methane, ${ }^{14} \mathrm{CO}_{2}$, or in the case of radon, through radioactive decay of radium. Few data exists on the formation of radioactive gases in a disposal facility. However, tritiated methane, ${ }^{14} \mathrm{CO}_{2},{ }^{14} \mathrm{CO}$, and other radioactive gases have been detected at the closed disposal sites at Sheffield [Streigel, 1985] and West Valley [Kunz, 1982; Matuszek, 1983].

Based on the above groups the following release mechanisms will be modeled:

a) Solubility limited;

b) Surface wash-off subject to partitioning;

c) Diffusion; and

d) Dissolution.

In general, a wasteform may release radionuclides by more than one mechanism. This will be allowed through user-supplied input. In particular, the user will be allowed to specify the fractional amount of mass released by each mechanism. For example, the user could specify that for $10 \%$ of the mass, release is controlled by partitioning, while the other $90 \%$ is controlled by diffusion. This flexibility may prove to be important when homogenizing the number of waste streams/wasteforms or in modeling large boxes containing many wasteforms.

Solubility-limited release will be modeled by allowing an instantaneous release of radionuclides into solution until the limit is reached. Further, if a solubility limit is specified and other release mechanisms are used to predict release, the amount released will be constrained such that the solubility limit is not exceeded. In general, the chemistry that occurs within a disposal facility is complex and changes in time due to the degradation of the waste containers and wasteforms. Obtaining reliable solubility limits in this environment is a difficult task. A y choice of solubility limits must be justified as conservative under all of the potential conditions. 
The surface wash-off model assumes that the radionuclides in the wasteforms with this release characteristic are available for release as soon as water contact occurs. Prior to water contact the radionuclides may be held on the surface by adsorption, chemisorption, adhesion, and ion-exchange among other factors. To account for these factors a partitior. factor, which is an equilibrium ratio relating the amount on the wasteform to that in solution, can be used. This partition factor depends on the properties of the wasteform and the local chemistry. The partition factor is a lumped parameter that covers many physical processes and obtaining reliable estimates may be difficult.

Experimental leaching data from solidified wastes often indicate that diffusion is the rate controlling process. In fact, the ANS16.1 standard leach test interprets the data in terms of diffusion [ANS, 1986].

Diffusion-controlled release is characterized by relatively high leach rates at early times then the rate continually decreases over time [Fig. 3]. In fact, analytically, the release rate, although it is integrable, approaches infinity as time approaches zero. For this reason, a release model based on a constant release rate may prove to be difficult to justify for diffusion controlled release. Choosing a constant release rate based on short term releases may be overly conservative while choosing the rate based on some type of average value may underpredict early releases. Therefore, one of the release models in the source term will be based on diffusion.

The diffusion model will consider the two geometries used most widely in LLW disposal: cylindrical (drums) and rectangular (boxes). To simplify the situation, it will be assumed that the concentration in the contacting solution is zero. That is, solution feedback effects are ignored. This assumption leads to the highest predicted release rates and permits an analytical solution to be obtained. The analytical solution can be adjusted to account for radioactive decay.

The dissolution model assumes that radionuclides are released congruently. The release rate is assumed to be constant in time and limited by solubility constraints. It would be appropriate for activated metals which undergo corrosion. In this case, the release rate could be estimated from corrosion data. The assumption of a constant release rate may be conservative for metallic corrosion as the data indicates decreasing corrosion rates in time [Romanoff, 1957; Gerhold, 1981].

\section{Release from Partially Failed Containers}

If the localized corrosion model is used, it will predict that a fraction of the container has failed. In this case, the release rate has to be limited to account for the restricted amount of water accessing the wasteform. In this model, it will be assumed that the release from a partially failed container is directly proportional to the ratio of the failed area to the total area of the container. 


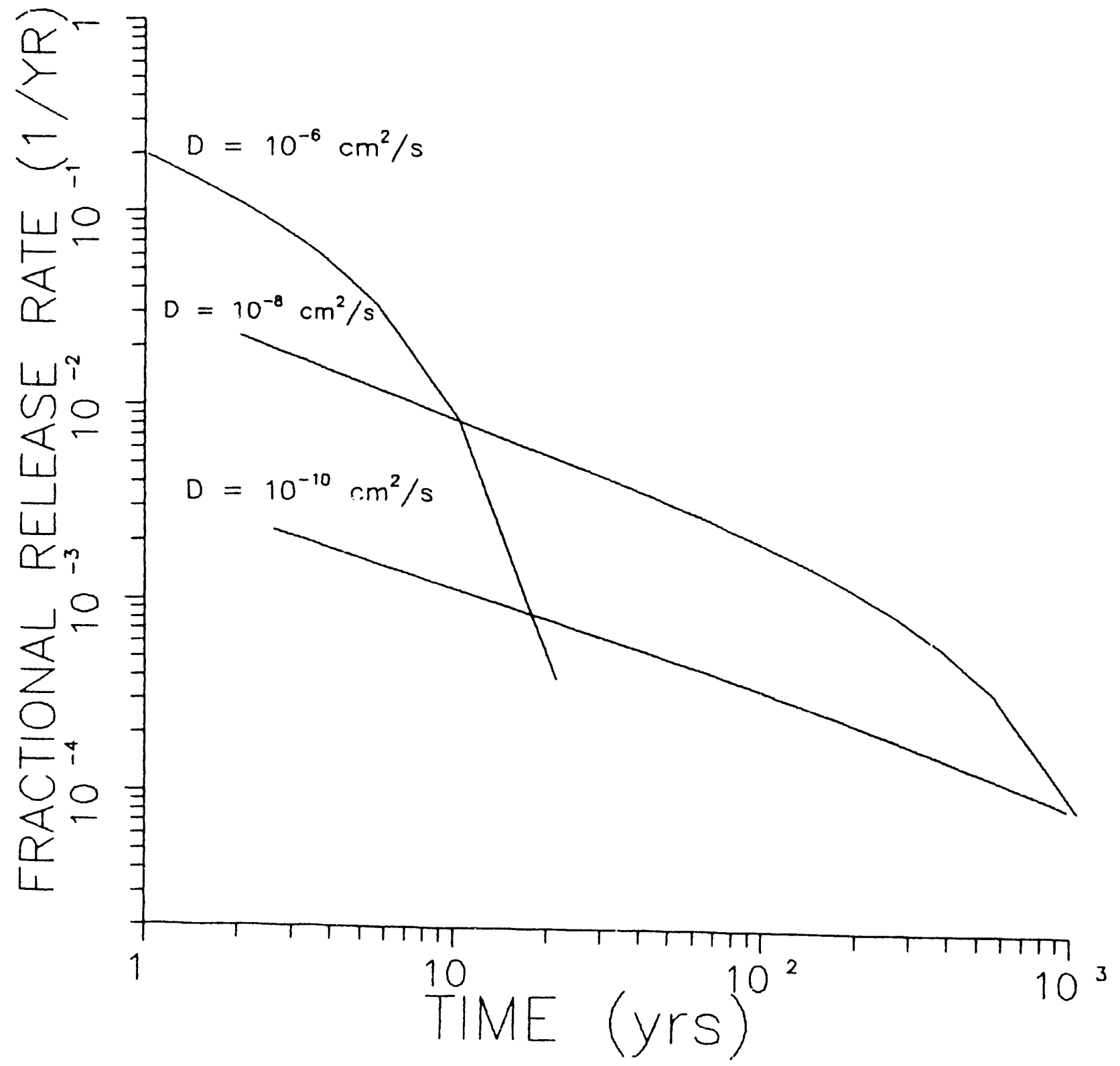

Figure 3 Diffusional fractional release rate from a cylinder $(\mathrm{r}=28 \mathrm{~cm}, \mathrm{~h}=85 \mathrm{~cm})$ as a function of time and diffusion coefficient. 


\subsubsection{Radionuclide Transport}

Two alternative methods have been selected to model transport within the disposal facility. The mixing cell cascade models [Fig. 4] used in the PAGAN performance assessment code have been generalized to allow more realistic estimation of the releases from the disposal facility while still retaining an analytical solution procedure. In cases where the assumptions used in obtaining the analytical solutions are not appropriate, a onedimensional finite difference model is provided.

Analytical predictions of release from the disposal facility will be made using an extension of the mixing cell cascade models presented in the performance assessment work of Sandia [Kozak, 1990]. The model used in PAGAN represents either uniform or sorptioncontrolled release from the wasteform. Migration is permitted only in the downward direction and facilitated by advection corrected for the effects of retardation. The model requires that the entire disposal facility perform as a single homogeneous source. That is, all containers fail simultaneously and all wasteforms release identically. The model does not represent explicit time-dependent (diffusion controlled) release from the wasteform nor does it explicitly model diffusion/dispersion within the disposal unit.

The mixing cell cascade model has been extended to permit each mixing cell to have a unique source. The containers within each mixing cell can fail separately leading to different starting times for release. In the improved model, the source is no longer limited to either a parition-limited or an exponentially decaying release rate. Both release modes are accommr,dated simultaneously. The assumption of constant release rate has been removed to allow an exponentially-decaying source. The details of this model are found in Appendix A.

The improved mixing cell cascade model is still limited by not permitting diffusion. controlled release from the wasteform. In theory, the analytical solutions used for diffusion controlled release from the wasteform could be used, the appropriate integrations carried out and the release from the disposal facility could be estimated. However, the analytical solutions for diffusion release are products of infinite series [see Appendix A] and thus the integrations, although conceptually simple, are quite complicated due to the number of terms. Therefore, at this time, diffusion-limited release will not be modeled directly. The potential for including a simplified diffusion release model to be used in conjunction with the mixing cell cascade approach may receive attention in the future.

As stated previously, the mixing cell cascade model does not model diffusional transport and does not allow for migration up towards the surface. Diffusional transport may be an important process during the time period when the engineered barriers provide protection against water flowing through the waste containing region of the facility. For these cases and to allow more flexibility in modeling release from the wasteform (i.e., diffusion controlled release), a numerical one-dimensional radionuclide transport model will be included in the options. 

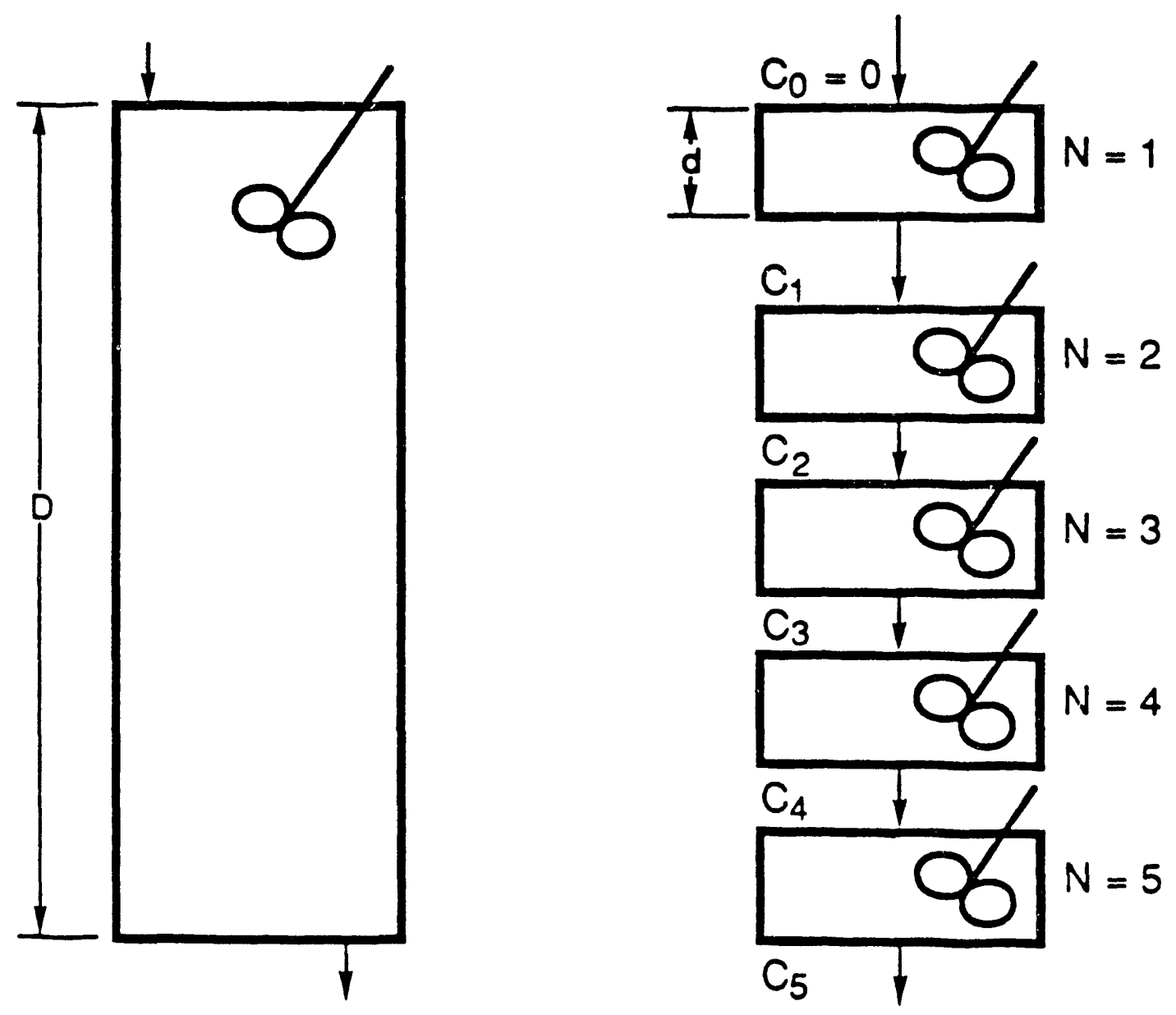

Figure 4 Schematic representation of the mixing cell cascade approach. (a) a single mixing cell, (b) multiple mixing cells. [From Kozak, 1990] 
The numerical model will be based on the method of finite differences and will include the processes of advection, dispersion, diffusion, retardation, and radioactive decay. The basic equations are provided in Appendix A.

The transport of gaseous radionuclides within the disposal facility requires special attention. For gases, flow will be up and out of the disposal facility. Upward migration will involve advection due to pressure variations that will vary seasonally and diurnally as well as diffusion. As revealed in the review of existing source term models, very little work has been performed in modeling gaseous release. However, examination of this problem has recently been initiated [Sullivan, 1991a; Pescatore, 1991].

As with water flow, prediction of the upward migration of gas is a complicated problem. Due to the length of time to be considered in a performance assessment, it is impractical to model daily or seasonal variations in gas flow rate. Therefore, it will be necessary for the code user to supply an average gas advection velocity in order to calculate gaseous release. This flow rate should be estimated using state-of-the-art computer codes or, as a minimum, chosen to permit conservative predictions of gas release.

For convenience, Table 1 presents a summary of the models selected for each of the four processes that influence release from the disposal facility.

\subsection{Probabilistic Modeling}

As currently envisioned, the source term model will be deterministic. That is, the code user will supply the necessary input parameters and the output will be the single-valued release rate as a function of time.

It is recognized that the models selected are very simplistic in nature and the input values may have a large uncertainty associated with them. Further, there will be a variation in the parameters controlling release in the actual disposal facility due to inhomogeneities in the wasteforms, containers, engineered structure, facility cover, etc. This situation naturally lends itself to probabilistic modeling where the input parameters are selected from within their expected range using a probabilistic sampling technique. After selection, the computer code is executed and the results tabulated. This sampling procedure is repeated several times and a distribution of expected release rates and their probability of occurrence is determined.

To extend the source term model to include the option of performing a probabilistic computation would require that the input be described using appropriate probability distribution functions, inclusion of a sampling routine, and allowing multiple calculations of the same problem while storing the results. 


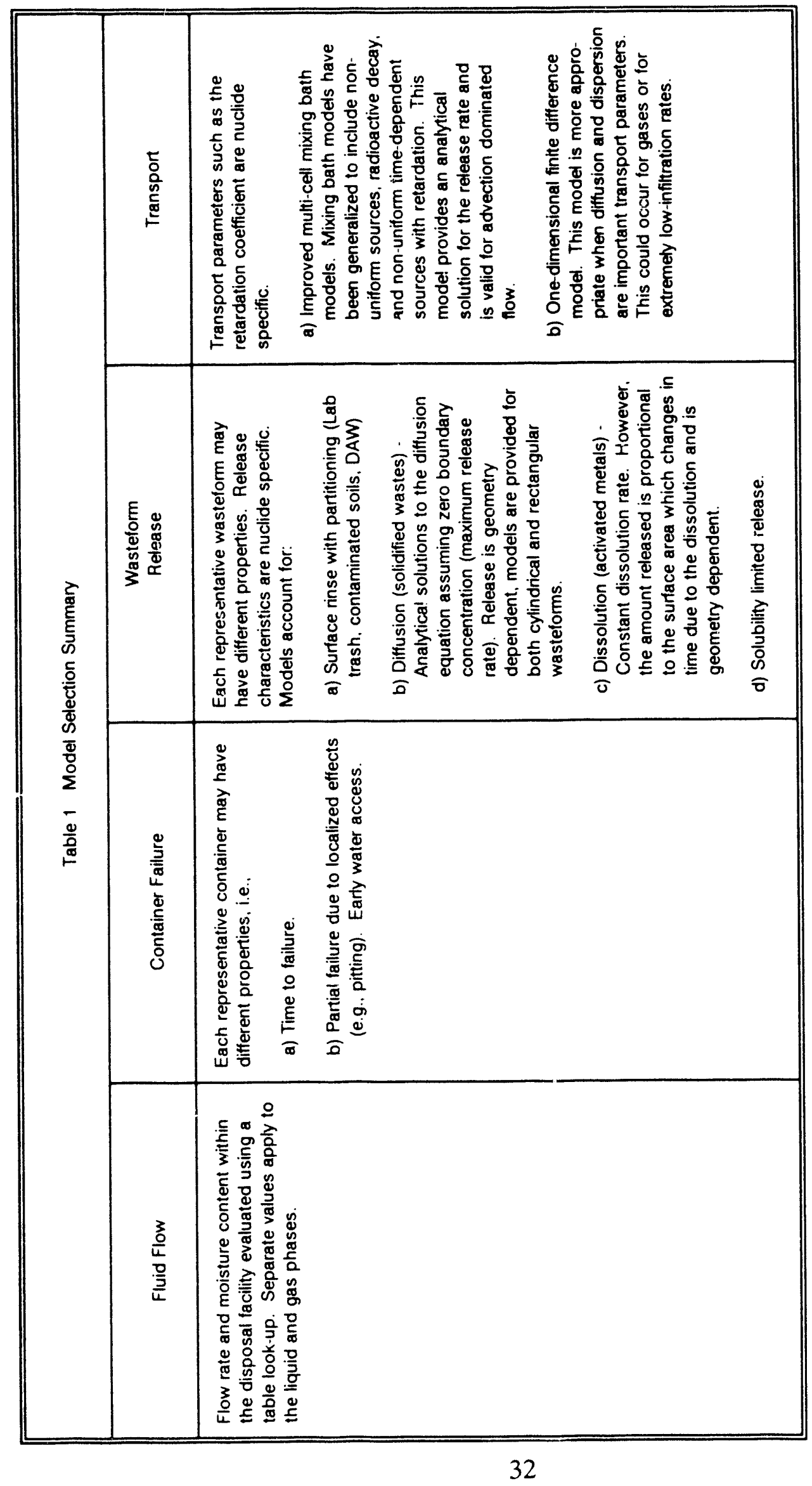


At this time the probabilistic approach will not be used. Currently, the data base will not easily support the determination of the parameter distribution functions required to describ the input. As more and better data become available, consideration of extension of the models to include a probabilistic approach may be warranted. 


\section{PROCEDURE FOR CALCULATING RELEASES FROM A DISPOSAL FACILITY}

The preceding chapter describes the models selected for estimating the source term but does not provide a clear indication of the steps needed to take the raw data, transform the data into the form required by the models, input the data and estimate the source term. Figure 5 is a schematic diagram that outlines this procedure.

The first step in this process is to compile the inventory data for the radionuclides of interest. Three factors that are determined before the waste is emplaced in a disposal facility figure prominently in determining release. These are the radionuclide's waste stream, wasteform, and container. A radionuclide contained in an activated metal will be released at a much different rate than the same radionuclide that exists as a surface contaminant on lab trash. Similar remarks apply for releases from different wasteforms. The container will control the time that release begins and for localized failure, the amount of water that accesses the waste.

From the review of existing source term computer codes it is clear that a major area that requires improvement is in the method of combining the different waste stream/wasteforms into a few representative wasteforms. In the past, explicit justification for grouping the

different waste streams has not been provided. Similar remarks apply to characterization of the waste containers.

Currently this project has an effort underway to determine the feasibility of characterizing the radionuclide inventory based on the three parameters listed above. This effort, based on commercial disposal data from 1987 through 1989 [Roles, 1990], will determine the activity fraction of the waste streams contained in various wasteform and container types (e.g. HIC's, carbon steel, etc.). As a result of this work we will determine the most important waste stream/wasteform/container systems in terms of activity.

Due to the large number of possible waste stream/wasteform/container combinations it will not be possible, nor even desirable, to model each of these systems individually. Therefore, many of the combinations that do occur will be lumped together to form a "representative" wasteform/container systems. This grouping will be performed to handle the most important wasteforms in terms of release. After the "representative" systems have been identified, appropriate container degradation and wasteform release models and parameters will be suggested.

Using the flexibility of the source term model, it will be possible to specify different release models and parameters for each waste stream/wasteform combination. For example, ion exchange resins solidified in cement may be assumed to follow diffusioncontrolled release with one diffusion coefficient while evaporator bottoms solidified in 


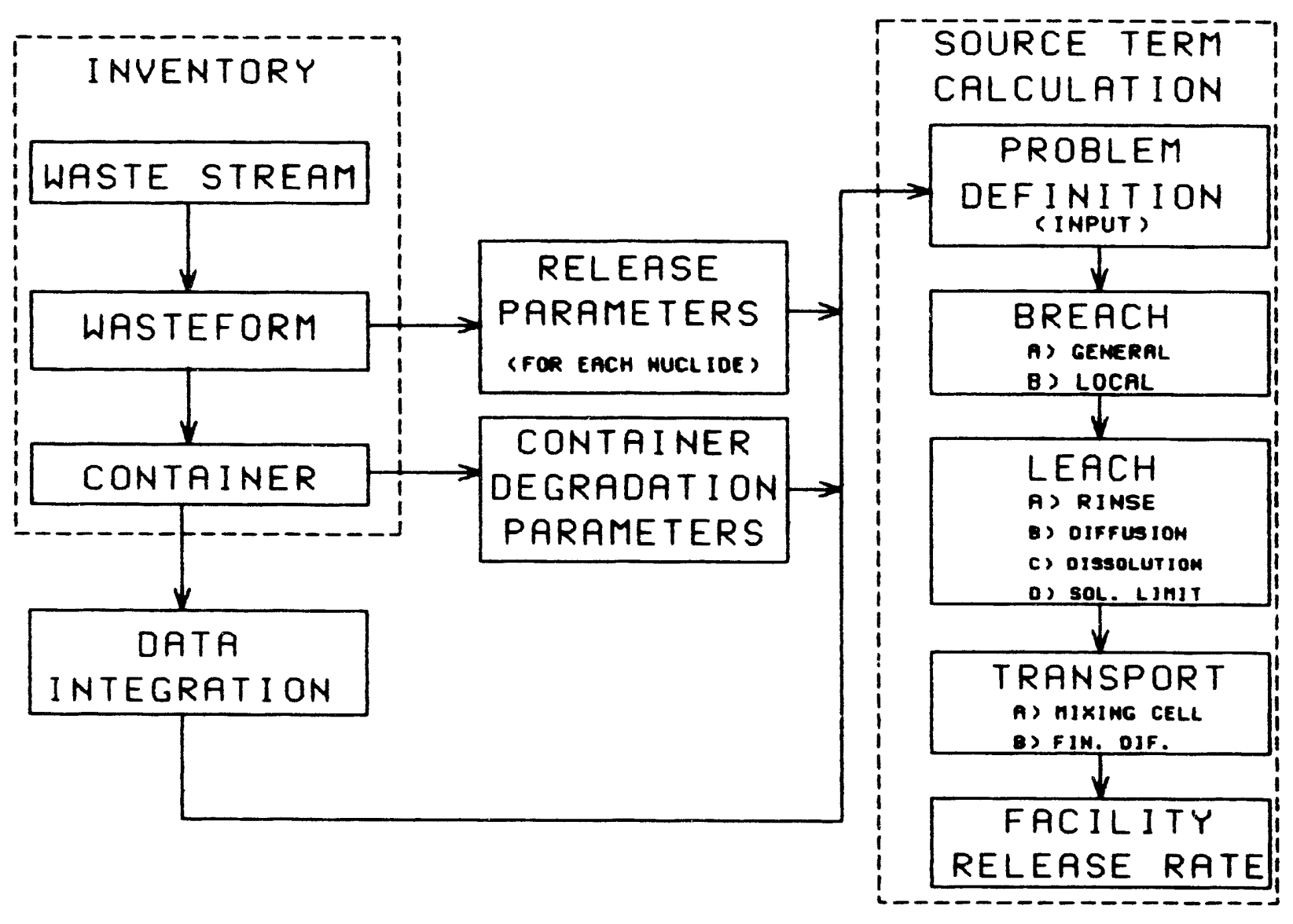

Figure 5 Flowchart of the procedure used to take waste stream/wasteform/container inventory data and define the necessary input parameters to estimate the release rate from a disposal facility. 
cement may be given another, and activated metals may be assumed to follow dissolution controlled release with a constant release rate. Similarly, for two identical waste stream/wasteforms in two separate containers, the predicted release can be different due to different container properties.

The inventory, container degradation and wasteform release parameters are input into the source term model as schematically depicted in Fig. 5. These parameters along with the radionuclide specific parameters (e.g. half-life, solubility limit, etc.), transport parameters, water flow parameters (velocity and moisture content), initial conditions, and boundary conditions (finite difference model only) fully describe the problem.

At this point the calculation is ready to proceed. For the mixing bath cascade model which relies on an analytical solution, the predicted release is calculated at the times specified through input. For the finite difference model, the predicted release is obtained through solving the differential equation describing release and transport through the disposal facility at a fixed time, incrementing the time and repeating the procedure until the problem is finished.

The output of these models will be the release rate from the disposal unit as a function of time. This output will be stored in tabular form for use with the PAGAN code which predicts the transport of radionuclides through the unsaturated zone to the aquifer and ultimately to a receptor. For gaseous release, a new performance assessment code is needed.

Two cases that involve transformation of the radionuclides require special attention:

a) production of gases due to microbial action and

b) ingrowth of radionuclides due to decay.

Very little work has been done to characterize the production rate of radioactive gases produced by biodegradation. However, tritiated methane, ${ }^{14} \mathrm{C}$-methane, and ${ }^{14} \mathrm{CO}_{2}$ have all been detected in the seepage gases at West Valley [Kunz, 1982] and Sheffield [Striegel, 1984]. While it is likely that the better disposal techniques (concrete vaults, no wooden or cardboard containers, solidification of the wastes in cement, etc.) planned for the new facilities may lead to less organic material, many of the wastes contain significant amounts of organics. This is particularly true for ${ }^{14} \mathrm{C}$ wastes [Gruhlke, 1986]. Therefore, releases caused by biodegradation cannot be dismissed at this time. More work is required in this area. 
By considering only one radionuclide at a time, ingrowth cannot be calculated directly. However, two approaches can be used to account for ingrowth depending on the half life of the daughter:

a) For daughter radionuclides that have a relatively long half-life as compared to the time frame considered for performance assessment, the production of the daughter can be calculated assuming that the parent is not removed from the wasteform. The maximum activity of the daughter during the time of performance assessment can then be determined. This maximum activity can be used as the initial activity of the daughter during the performance assessment. This is explained in Figure 5 which shows the decay chain for ${ }^{241} \mathrm{Pu}\left(\mathrm{T}_{1 / 2}=87\right.$ yrs. $)$ to ${ }^{241} \mathrm{Am}\left(\mathrm{T}_{1 / 2}=458\right.$ yrs. $)$ to ${ }^{237} \mathrm{~Np}$ $\left(\mathrm{T}_{1 / 2 .}=2.1410^{6} \mathrm{yrs}\right.$.). From Figure 6 , the maximum americium activity is approximately $3 \%$ of the initial plutonium activity and occurs after 100 years. For performance assessment the initial americium activity could be increased by this amount. If desired, the activity could be further increased to insure that the initial americium activity was large enough to allow the decayed americium activity to equal the maximum activity due to ingrowth at the time of the maximum.

b) For daughter products with short half-lives as compared to the period of performance assessment, the mass balance equation for the daughter product can be altered to include production due to decay. For example, ${ }^{222} \mathrm{Rn}$ has a four day half-life and is produced by decay of ${ }^{226} \mathrm{Ra}$ with a 1600 year half-life. Due to the differences in half-lives, radon reaches secular equilibrium with radium within one year. After this time, the activity of these two nuclides is identical. However, setting the initial radon inventory to the radium inventory would (due to radioactive decay) predict that there is essentially no radon after one year. This can be overcome by setting the activity of ${ }^{222} \mathrm{Rn}$ in the waste form equal to the activity of ${ }^{226} \mathrm{Ra}$ at all times. This requires inclusion of a production term in the wasteform mass balance routines. 


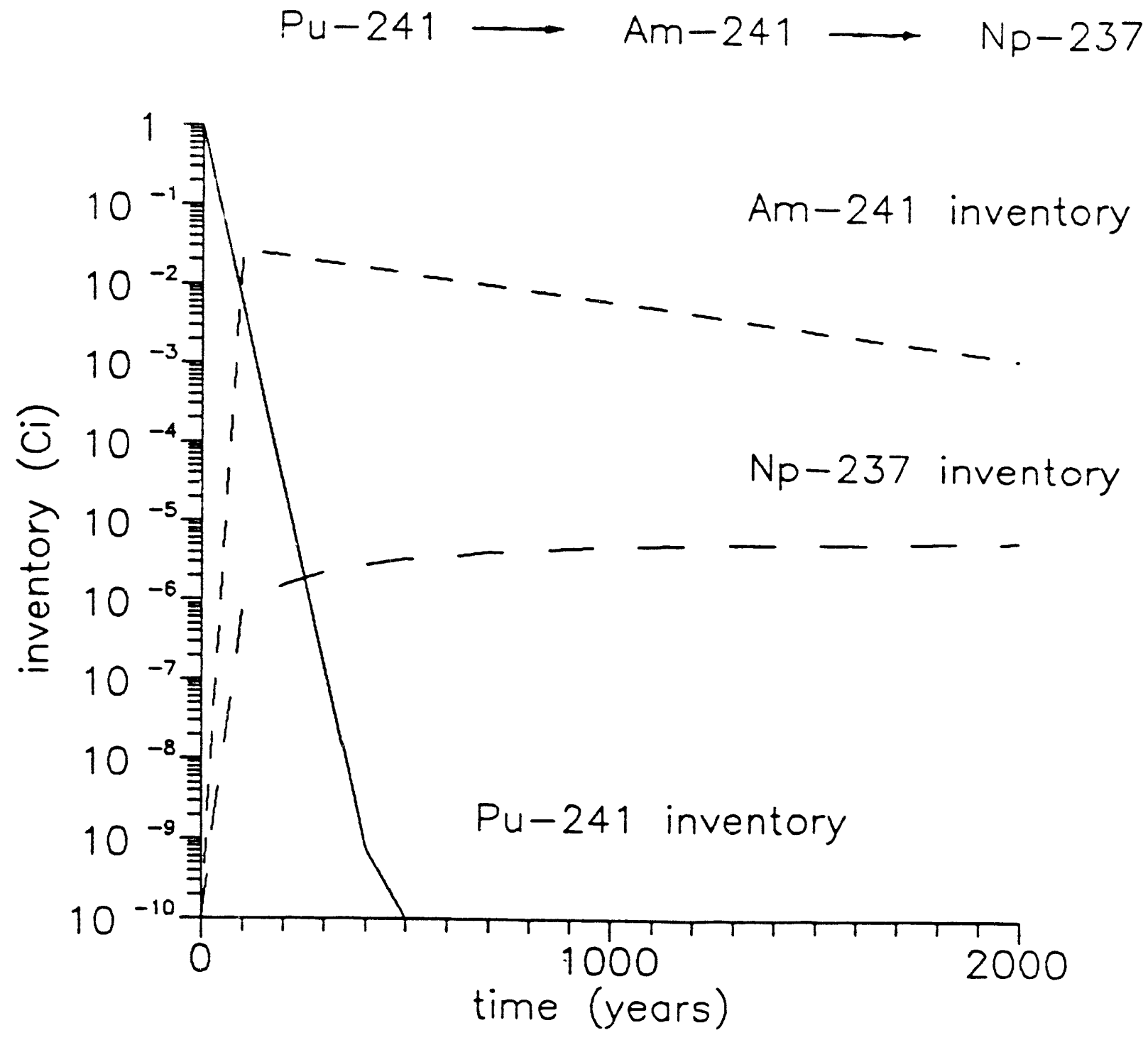

Figure 6 Pu-241 radioactive decay chain. The maximum activity of the daughter species can be used in estimating an adjusted inventory of the daughters without explicitly considering decay of the parent. [From Kozak, 1990] 


\section{CONCLUSIONS}

A framework for performing estimates of the source term from a LLW disposal facility has been developed. Within this framework, models to predict the important processes (fluid flow, container degradation, wasteform leaching, and radionuclide transport) related to release and transport of radionuclides within the disposal facility have been recommended.

The proposed source term model improves upon existing models in that more flexibility is allowed in order to model the various waste stream/wasteform/container systems while still retaining relatively simple models that do not require extensive computer time or provide an undue burden on the code user in terms of input requirements.

The recommended models are improvements over those that currently exist, yet still retain a simplified structure in their treatment of the complex phenomena involved in the release and transport of radionuclides within a disposal facility. As such, the models are prone to misuse through improper choice of the input parameters. Enough emphasis cannot be placed on the need for justification and documentation of the choices for the input parameters.

A priori this source term model, as all others, cannot be relied on to provide release rate estimates that are highly accurate with respect to the real world situation. The proposed source term model, because of its ability to compute release rates quickly, will be extremely useful for screening to determine the radionuclides released at the highest rate, parameter sensitivity analyses, and, with proper choice of the input parameters, provide upper bounds to release rates. 


\section{REFERENCES}

[ANS, 1986]

American Nuclear Society, "Measurement of the Leachability of Solidified Low-Level Radioactive Wastes," Prepared by the American Nuclear Society Standards Committee Working Group ANS-16.1, 1986.

[Bajurny, 1991]

F.J. Bajurny, "Ontario Hydro's Long-Term Low-Level Radioactive Waste Storage Experience," Low-Level Waste Management Seminar, Electric Power Research Institute, Boulder, CO, June 20-21, 1991.

[Bennett, 1984]

R.D. Bennett, et. al., "Alternative Methods for the Disposal of Low-Level Radioactive Wastes Task 1: Description of Methods and Assessment of Criteria," Vol. 1, NUREG/CR3774, U.S. Army Engineer Waterways Experiment Station, Vicksburg, MS, 1984.

[Bowerman, 1990a]

B.S. Bowerman, "Method for Identifying Significant Radionuclides in Low-Level Waste," Technical Letter Report to the U.S. Nuclear Regulatory Commission, WM-1409-1, Brookhaven National Laboratory, 1990.

[Bowerman, 1990b]

B.S. Bowerman, "Method for Grouping Low-Level Waste Streams," Technical Letter Report to the U.S. Nuclear Regulatory Commission, WM-1409-2, Brookhaven National Laboratory, 1990.

[Chu, 1991]

M.S.Y. Chu, M.W. Kozak, J.E. Campbell, and B.M. Thompson, "A Self-Teaching Curriculum for the NRC/SNL Low-Level Waste Ferformance Assessment Methodology," NUREG/CR5539, SAND90-0585, Sandia National Laboratories, 1991.

[Clifton, 1989]

J.R. Clifton and L.I. Knab, "Service Life of Concrete," NUREG/CR-5466, NISTIR89-4086, U.S. Nuclear Regulatory Commission, 1989.

[CPG, 1987]

V. Rogers, C. Hung, "PRESTO-EPA-CPG: A Low-Level Radioactive Waste Environmental Transport and Risk Assessment Code, Methodology and Users Manual," EPA 520/1-87-026, RAE 8706/1-4, Environmental Protection Agency, 1987.

[DOE, 1987]

Conference of Radiation Control Program Directors, Inc., "Compilation of State-by-State Low-Level Radioactive Waste Information," DOE/ID/12377-T1, October, 1987. 
[DOE, 1990]

U.S. Department of Energy, "Integrated Data Base for 1990: U.S. Spent Fuel and Radioactive Waste Inventories, Projections, and Characteristics," DOE/RW-0006, Rev. 6, Oak Ridge National Laboratory, October, 1990.

[EPA, 1988]

U.S. Environmental Protection Agency, "Low-Level and NARM Radioactive Wastes, Draft Environmental Impact Statement for Proposed Rules, Volume 1, Background Information Document," EPA 520/1-87-012-1, June, 1988.

[FR, 1982]

Federal Register, "Licensing Requirements for Land Disposal of Radioactive Waste," Vol. 47, No.248, Monday, December 27, 1982.

[Gee, 1988]

G.W. Gee and D. Hillel, "Groundwater Recharge in Arid Regions: Review and Critique of Estimation Methods," Hydrological Processes, Vol. 2, p. 255-266, 1988.

[Geihold, 1981]

W.F. Gerhold, E. Escalante, and B.T. Sanderson, "The Corrosion Behavior of Selected Stainless Steels in Soil Environments," NBSIR 81-2228, National Bureaי of Standards, 1981.

[Gruhlke, 1986]

J.M. Gruhlke, J. Neiheisel, and L. Battist, "Estimates of the Quantities, Form and Transport of Carbon-14 in Low-Level Radioactive Waste," EPA 520/1-86-019, U.S. Environmental Protection Agency, 1986.

[Higginbotham, 1983]

L.R. Higginbotham, "Final Waste Classification and Waste Form Technical Position Papers," United States Nuclear Regulatory Commission, May 11, 1983.

[Huyakorn, 1989]

P.S. Huyakorn, J.B. Kool, and J.B. Robertson, "VAM2D - Variably Saturated Analysis Model in Two Dimensions," NUREG/CR-5352, HGL/89-01, HydroGeoLogic, Inc., 1989.

[Kozak, 1989]

M.W. Kozak, et. al., "Background Information for the Development of a Low-Level Waste Performance Assessment Methodology: Selection and Integration of Models," NUREG/CR5453, SAND89-2509, Volume 3, Sandia National Laboratories, 1989.

[Kozak, 1989a]

M.W. Kozak, et. al., "Background Information for the Development of a Low-Level Waste Performance Assessment Methodology: Identification and Recommendation of Computer Codes," NUREG/CR-5453, SAND89-2509, Volume 4, Sandia National Laboratories, 1989. 
[Kozak, 1990]

M.W. Kozak, et. al., Background Information for the Development of a Low-Level Waste Performance Assessment Methodology: Computer Code Implementation and Assessment," NUREG/CR-5453, SAND89-2509, Volume 5, Sandia National Laboratories, 1990.

[Kunz, 1982]

C.O. Kunz, "Radioactive Gas Production and Venting at a Low-Level Radioactive Waste Burial Site," Nucl. Chem. Waste Management, Vol. 3, p. 185, 1982.

[Lohaus, 1991]

P.H. Lohaus, "Waste Form Technical Position, Revision 1," U.S. Nuclear Regulatory Commission, January 24, 1991.

[Longsine, 1987]

D.E. Longsine, E.J. Bonano, and C.P. Harlan, "User's Manual for the NEFTRAN Computer Code," NUREG/CR-4766, SAND86-2405, Sandia National Laboratories, 1987.

[Looney, 1987]

B.B. Looney, M.W. Grant, and C.M. King, "Estimation of Geochemical Parameters for Assessing Subsurface Transport at the Savannah River Plant," DPST-85-904, DE87-013051, E.I. duPont de Nemours \& Co., 1987.

[Matuszek, 1983]

J.H. Matuszek and L.W. Robinson, "Respiration of Gases from Near-Surface Radioactive Waste Burial Trenches," Waste Management '83, ed. R.G. Post, pp. 423 - 427, Tucson, AZ, 1983.

[Mughabghab, 1989]

S.F. Mughabghab and T.M. Sullivan, "Evaluation of the Pitting Corrosion of Carbon Steels and Other Ferrous Metals in Soil Systems," Waste Management, Vol. 9, pp. 239-251, 1989.

[Otzunali, 1981]

O.I. Otzunali, G.C. Re', P.M. Moskowitz, E.D. Picazo, and C.J. Pitt, "Data Base for Radioactive Waste Management: Impact Analyses Methodology Report," NUREG/CR1759, Vol. 3, Dames and Moore, 1981.

[Otzunali, 1986]

O.I. Oztunali and G.W. Roles, "Update of Part 61 Impacts Analysis Methodology," NUREG/CR-4370, Vol. 1,1986.

[Pescatore, 1991]

C. Pescatore and T.M. Sullivan, "Low-Level Waste Source Term Evaluation, Quarterly Progress Report: January - March 1991," WM-3276-14, Brookhaven National Laboratory, 1991. 
[POP, 1987]

D.E. Fields, C.A. Little, F. Parraga, V. Rogers, and C. Hung, "PRESTO-EPA-POP: A LowLevel Radioactive Waste Environmental Transport and Risk Assessment Code - Volume 1, Methodology Manual," EPA 520/1-87-024-1, RAE 8796/1-1, Environmental Protection Agency, 1987.

[Roles, 1990]

G.W. Roles, "Characteristics of Low-Level Radioactive Waste Disposed During 1987 Through 1989", NUREG-1418, U.S. Nuclear Regulatory Commission, 1990.

[Romanoff, 1957]

M. Romanoff, "Underground Corrosion," National Bureau of Standards Circular 579, 1957.

[Shuman, 1991]

R. Shuman, N. Chau, and V. Rogers, "Improved Modeling of Engineered Barriers for LowLevel Waste Disposal," presented at Waste Management '91, Tucson, AZ, 1991.

[Soo, 1990]

P. Soo and L.W. Milian, "The Impact of LWR Decontaminations on Solidification, Waste Disposal and Associated Occupational Exposure," NUREG/CR-3444, BNL-NUREG-51699, Vol. 7, Brookhaven National Laboratory, 1990.

[Starmer, 1988]

R.J. Starmer, L.R. Deering, and M.F. Weber, "Performance Assessment Strategy for LowLevel Waste Disposal Sites," in the Tenth Annual DOE Low-Level Waste Management Conference, Denver, 1988.

[Streigel, 1985]

R.G. Streigel, "Methods for Determining the Transport of Radioactive Gases in the Unsaturated Zone," Department of Energy Low-Level Waste Management Participants Meeting, p. 579 - 587, Denver, CO., 1985.

[Sullivan, 1988]

T.M. Sullivan, C.R. Kempf, C.J. Suen, and S.M. Mughabghab, "Low-Level Radioactive Waste Source Term Model Development and Testing," NUREG/CR-5204, BNL-NUREG52160, U.S. Nuclear Regulatory Commission, 1988.

[Sullivan, 1988a]

T.M. Sullivan, C.J. Suen, and E. Sweeney, "Low-Level Waste Source Term Evaluation Quarterly Progress Report: July - September, 1988," WM-3276-7, Brookhaven National Laboratory, 1988. 
[Sullivan, 1989]

T.M. Sullivan and C.J. Suen, "Low-Level Waste Shallow Land Disposal Source Term Model: Data Input Guides," NUREG/CR-5387, BNL-NUREG-52206, U.S. Nuclear Regulatory Commission, 1989.

[Sullivan, 1991]

T.M. Sullivan and C.J. Suen, "Low-Level Waste Source Term Model Development and Testing," NUREG/CR-5681, BNL-NUREG-52280, U.S. Nuclear Regulatory Commission, 1991.

[Sullivan, 1991a]

T.M. Sullivan and C. Pescatore, "Low-Level Waste Source Term Evaluation, Quarterly Progress Report: October - December 1990," WM-3276-13, Brookhaven National Laboratory, 1991.

[Travis, 1991]

B.T. Travis and K.H. Birdsell, "TRACR3D: A Model of Flow and Transport in Porous Media: Model Description and User's Manual," LA-11798-M, Los Alamos National Laboratory, 1991.

[Walton, 1990]

J.C. Walton, L.E. Plansky, and R.W. Smith, "Models for Estimation of Service Life of Concrete Barriers in Low-Level Radioactive Waste Disposal," NUREG/CR-5542, EGG2597, U.S. Nuclear Regulatory Commission, 1990.

[Yeh, 1987]

G.T. Yeh, "FEMWATER: A Finite Element Model of Water Flow Through SaturatedUnsaturated Porous Media - First Revision," ORNL-5567/R1, Oak Ridge National Laboratory, 1987. 


\section{APPENDIX A \\ MATHEMATICAL DESCRIPTION OF THE MODELS SELECTED FOR SOURCE TERM ANALYSIS}

The mathematical details pertaining to the models selected for source term analysis are described in this Appendix. The justification for selecting these particular models may be found in Chapter 4 of this report and is not repeated here. The models cover the processes of water flow, container degradation, waste form leaching, and radionuclide transport.

There are no models, per se, for the disposal facility radionuclide inventory. Rather, the inventory will be treated as a known quantity. The methodology required to obtain the inventory is also discussed in Chapter 4.

A flowchart that describes the procedure for taking the radionuclide inventory, defining the problem, and calculating the release rate from the facility (e.g., the source term) is presented in Figure A.1.

\section{FLUID FLOW}

The water advection velocity will be supplied by the user as a function only of time through tabular input. For gaseous releases, the gas advection velocity will be supplied similarly.

Therefore, the advection velocities can be written as:

$$
\begin{aligned}
& v_{\mathrm{w}}=f(t) \\
& v_{\mathrm{g}}=g(t)
\end{aligned}
$$

where $v_{w}$ is the volumetric flow velocity (Darcy velocity) of the water, $v_{g}$ is the volumetric flow velocity of the gas, and $f(t)$ and $g(t)$ are the user-supplied velocities.

\section{CONTAINER DEGRADATION}

Two types of failure are considered in the source term model: general and local. General failure of the containers is assumed to occur at a user-specified time. After general failure it is assumed that the container no longer provides a barrier to water flow. Local failure of the container occurs prior to general failure and permits access of water to the wasteform to occur at earlier times. 


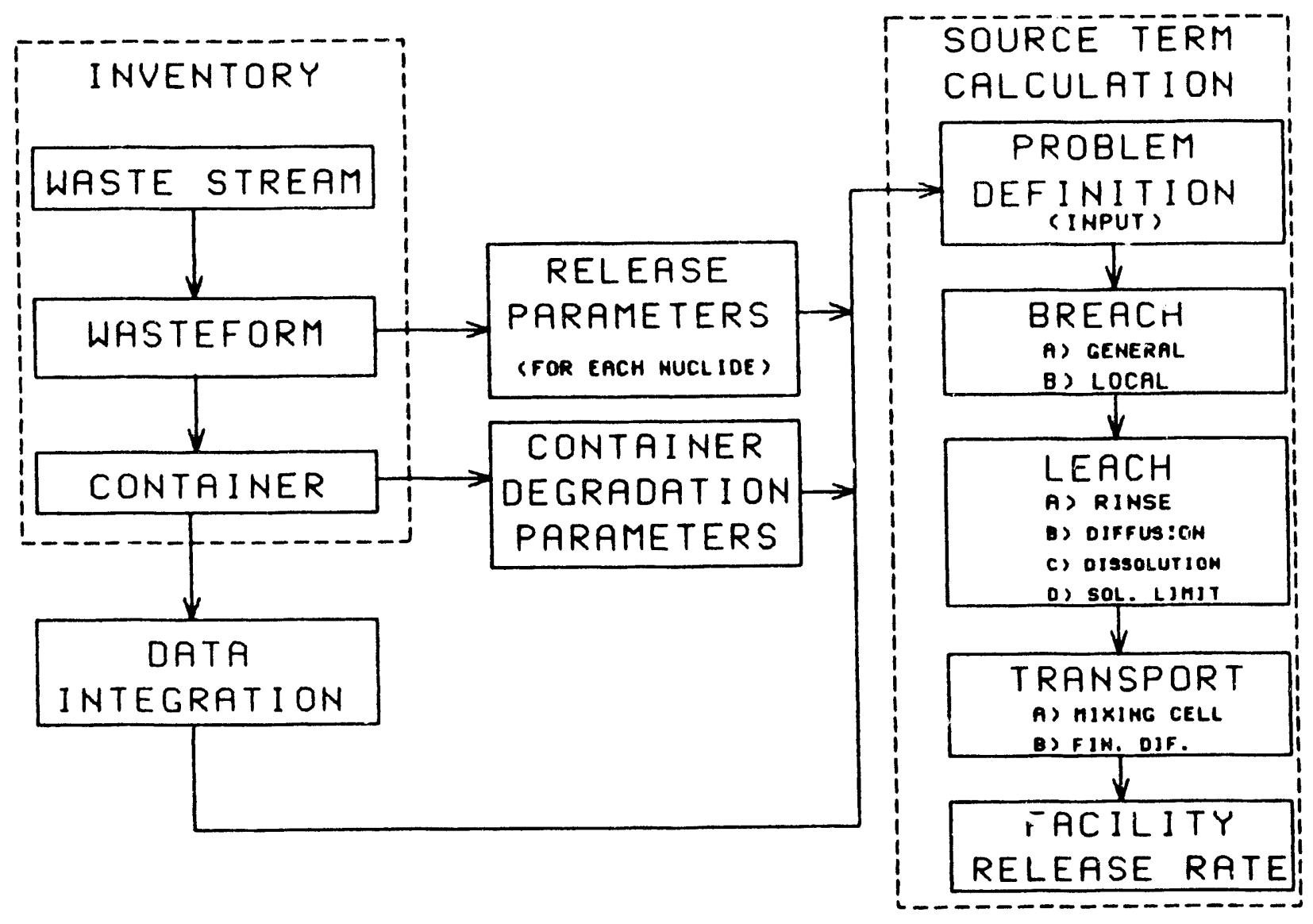

Figure A.1 Flowchart of the procedure used to take waste stream/wasteform/container inventory data and define the necessary input parameters to estimate the nuclide specific release rate from a disposal facility. 
General failure is modeled through a user-specified failure time for each container. For metal containers it may be estimated by dividing the metal thickness by the expected corrosion rate. For non-metallic container materials, other methods will be needed to estimate the time to failure.

Localized failure on metals can occur due to pitting, stress corrosion cracking, or other mechanisms. In these failure scenarios, water will access the waste form much earlier than predicted by general corrosion. However, only a small portion of the container will permit water access to the waste form. The reduced water flow impacts on the amount released from the waste form. This is accounted for in the leaching model.

Localized failure will be modeled similar to the approach used in the BLT code [Sullivan, 1989]. This model was originally developed for pitting of carbon steel drums. The breached area. $A_{b}$, is estimated from the following relationship:

$$
A_{\mathrm{b}}=N_{\mathrm{p}} A_{\mathrm{c}} \pi\left(h^{2}-T^{2}\right)
$$

where:

$\mathbf{N}_{p}$ is the number of localized failures per unit area of the container;

$A_{c}$ is the total container area;

$\mathrm{T}$ is the thickness of the metal; and

$h$ is the penetration depth.

If the penetration depth, $h$, is less than the metal thickness, the container has not been penetrated and the breached area is set to zero.

The penetration depth is estimated from the expression:

$$
h=k t^{\mathrm{n}}
$$

Where $\mathrm{t}$ is time in years, and $\mathrm{k}$ and $\mathrm{n}$ have been determined for carbon steel [Mughabghab, \$988! based on the NBS corrosion data in soils [Romanoff, 1957; Gerhold, 1981]. For carbon steel, the parameter $\mathrm{k}$ was found to depend on the soil-water $\mathrm{pH}$ and the parameter $n$ depends on the degree of soil aeration, moisture content, and clay content. The value for $\mathrm{n}$ is always less than 1 and is higher for poorly aerated soils (poor drainage) as compared to well aerated soils. 
A detailed discussion of the choice of values for $\mathrm{N}_{\mathrm{p}}, \mathrm{k}$ and $\mathrm{n}$ can be found in the BLT data input guides [Sullivan, 1989]. For carbon steels, $N_{p}$ was found to range from 0.05 to 0.5 per $\mathrm{cm}^{2}$, the average value for $\mathrm{k}$ was $0.0457 \mathrm{~cm} / \mathrm{yr}^{\mathrm{n}}$ and $\mathrm{n}$ ranged from 0.01 to 0.93 .

For stairiless steels. even though there are 14 years of corrosion data in 15 different soils [Romanoff, 1957; Gerhold, 1981], the data are insufficient to support estimation of the necessary parameters. Thus, for these and other container materials, the parameters will have to be estimated using engineering judgement if localized corrosion is to be modeled.

Through proper choice of the localized corrosion parameters, failure of the passive gas vents required on HIC's may also be modeled. For example, by setting $n$ to zero and appropriate choice of the parameters $h$ and $N_{p}$, a constant area of failure may be estimated. This failure area may be particularly important if gaseous release is being modeled.

\section{WASTEFORM LEACHING}

Four processes are considered in estimating the release of radioactivity from the waste form: solubility limited release, surface rinse with partitioning, diffusion, and dissolution. These are discussed in the following subsections.

\section{Solubility Limited Release}

This model assumes that release is constrained by the solubility limit for the particular radionuclide. That is, the amount of radionuclide mass released from the wasteform at each time step is calculated to insure that the concentration of that nuclide in solution is equal to the solubility limit. This is continued until the inventory of the waste form is depleted to the point that release of the total remaining radionuclide mass in the wasteform is insufficient to bring the solution concentration up to the solubility limit.

Thus, the model takes the form:

$$
C=C_{\text {sat }}
$$

where:

$\mathrm{C}=$ solution concentration, and

$\mathrm{C}_{\text {sat }} \quad=$ solubility limit.

The mass released from the wasteform is calculated at each time step as the mass necessary to bring the concentration up to the solubility limit. In general, this will be determined by the rate of radionuclide transport away from the wastes. 
For several wastes stacked one on top of another, release will be from the top downwards. That is, assuming that all containers breach at the same time, each container will release enough mass to reach the solubility limit for the radionuclide under consideration. After this time, the wasteform on top will continue to release mass as advection and other transport processes move the radionuclides downward. However, because the transport properties (flow rate) are assumed uniform throughout the disposal facility, the wasteforms beneath the top one will not release any more mass until the top one becomes depleted. After this time, the second wasteform in the stack will begin to release mass and this will continue down through the stack of wasteforms.

In general, reliable estimates for the solubility limits will be difficult to obtain due to the wide variety of chemical constituents expected in the disposal facility. If a solubility limit is selected in this model it will be applied to the entire facility.

\section{Rinse Release with Partitioning}

Radionuclides contained on the surface of the wasteform may be released on contact with water with the constraint that there is an equilibrium between the amount remaining on the surface and that in solution. This equilibrium is expressed in terms of a partition coefficient, $\mathrm{K}_{\mathrm{d}}$. The partition coefficient is the ratio of the mass adsorbed on the solid per unit mass of the solid divided by the concentration in solution.

In modeling a disposal facility, the properties of the facility are homogenized within a computational cell (the definition of a computational cell is discussed in the transport modeling section). Therefore, the partition coefficient should be chosen as the average for all of the materials within the region of interest. For a region containing wasteforms, soil, corroded metal containers, and concrete from an engineered barrier, the partition coefficient should be an average accounting for the different amounts of each material. An assumption of the mixing cell cascade transport model is that a single retardation coefficient representative of the entire disposal facility must be used. This is discussed further in the section on the mixing cell cascade model.

Equilibrium between the solution and the solids is assumed to occur instantly after container breach at time $\tau_{\mathrm{b}}$. One method for expressing this release rate, $\mathrm{Q}$, is:

$$
Q=M(t) \delta\left(t-\tau_{b}\right)
$$

where:

$$
\begin{array}{ll}
M(t) & =M_{r} e^{-(\lambda t) / R ;} \\
M_{r} & =\text { rinse mass available at } t=0 ; \\
\lambda & =\text { radioactive decay constant; }
\end{array}
$$




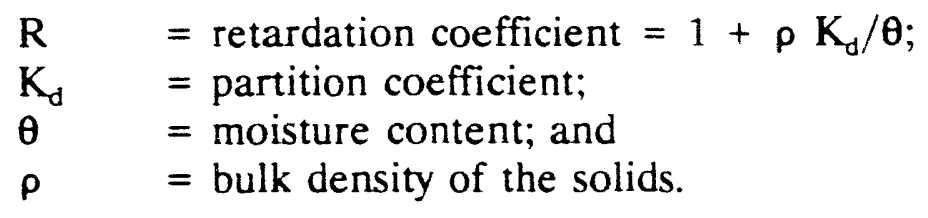

The model assumes that all of the rinse mass is released upon breach. Equation (A.6) calculates the amount that enters solution (the rest of the mass is adsorbed on the solids). As mass in solution is removed due to transport or decay, mass adsorbed to the solids is released to solution to maintain the local equilibrium. In the present form, Eqn. (A.6) is useful in the mixing cell cascade model which analytically integrates the release term. However, due to the $\delta$ function, it is not useful for the finite difference model.

For the finite difference model, the mass released to solution is calculated by requiring equilibrium between the solid and solution to be maintained at the beginning of each time step. As mass is transported away over the numerical integration time step, equilibrium is no longer maintained. Therefore, the procedure is repeated at the beginning of each time step. This following expression for the mass release rate to solution arises:

$$
q(t)=\frac{M(t)\left(1-\frac{C}{C_{\text {sat }}}\right)}{\theta V \Delta t}
$$

where:

$q(t) \quad=$ release rate per unit volume;

$M(t)=$ mass released at time $t$ to maintain equilibrium;

$\mathrm{C}(\mathrm{t})=$ solution concentration at time $\mathrm{t}$;

$\mathrm{V} \quad=$ volume of the finite difference node; and

$\Delta \mathrm{t}=$ time step size.

After performing the mass balance at the beginning of the time step, $M(t)$ can be estimated from [Sullivan, 1991a]:

$$
M(t)=\frac{\left(M_{\mathrm{r}}(t)-\frac{\rho K d}{\theta} M_{\mathrm{s}}(t)\right)}{R}
$$


where:

$\mathrm{M}_{\mathrm{r}}(\mathrm{t})=$ the rinse mass available at time $t$, which is the original rinse mass minus any mass that has been released or lost to radioactive decay.

Also,

$M_{s}(t)=C(t) \theta V=$ mass in solution at time $t$.

\section{Diffusion-Controlled Release}

Conceptually, release from many solidified wasteforms can be described as a diffusioncontrolled process. Two models, differing only in geometry, are provided. In these models, it is assumed that, at the outer edge of the wasteform, the radionuclide concentration is zero. This assumes that transport processes away from the wasteform are fast enough to remove any radionuclides supplied by diffusion out of the wasteform. Although this situation will never be realized exactly, it does provide for the maximum diffusive release rate from the wasteform. Further, in many cases of practical interest, the solution concentration outside of the wasteform will not increase to a level such that it will markedly influence release.

In both models, we analytically solve the diffusion equation corrected for decay.

$$
\frac{\partial C}{\partial t}=\nabla \cdot D \nabla C-\lambda C
$$

where $\mathrm{D}=$ the effective diffusion coefficient and all other parameters have been previously defined.

The initial condition assumes a uniform concentration throughout the wasteform:

$$
C(x, y, z, 0)=C_{\mathrm{o}}
$$

The boundary conditions assume symmetry about the midplane of the wasteform and zero concentration at the outer edge. 


$$
\begin{aligned}
& C\left(x_{\mathrm{b}}, y, z, t\right)=0 \\
& C\left(x, y_{\mathrm{b}}, z, t\right)=0 \\
& C\left(x, y, z_{\mathrm{b}}, t\right)=0
\end{aligned}
$$

where the subscript b denotes a boundary.

Solution of Eqn. (A.9) subject to the initial and boundary conditions gives the concentration at any location within the wasteform. However, the quantity of interest is the release rate, which is the mass flux integrated over the surface area.

$$
Q(t)=\int d S \cdot J_{s}
$$

where:

$\mathrm{Q}(\mathrm{t})$ is the mass release per unit time; and $\mathrm{J}_{\mathrm{s}}$ is the mass flux at the surface.

For one-dimensional diffusion-controlled release,

$$
J_{\mathrm{s}}=-D \frac{\partial C\left(x_{\mathrm{s}}\right)}{\partial x}
$$

where $\mathrm{x}_{\mathrm{s}}$ denotes a surface of the wasteform.

\section{Cylindrical Geometry}

The expression for the mass release rate from a cylindrical wasteform of height, $2 \mathrm{~L}$, and radius $\mathrm{R}$ is [Pescatore, 1991]:

$$
Q(t)=Q_{r}(t)+Q_{2}(t)
$$


where:

$$
Q_{\mathrm{r}}(t)=Q_{\mathrm{r}}(\lambda ; t)=\frac{32}{\pi^{2} R^{2}} \cdot D C_{\mathrm{o}} V e^{-\lambda t} S_{\mathrm{p}}(t) S_{\mathrm{q}}(t)
$$

and

$$
Q_{\mathrm{z}}(t)=Q_{\mathrm{z}}(\lambda ; t)=\frac{8}{L^{2}} \cdot D C_{\mathrm{o}} V e^{-\lambda t} S_{\mathrm{c}}(t) S_{\mathrm{d}}(t)
$$

Here.

$$
\begin{aligned}
& S_{c}(t)=\sum_{m=1}^{\infty} \frac{e^{-(\beta m / R)^{2} D t}}{\left(\beta_{m}\right)^{2}} \\
& S_{p}(t)=\sum_{n=1}^{\infty} \frac{e^{-(2 n-1) \pi / 21)^{2} D t}}{(2 n-1)^{2}} \\
& S_{q}(t)=\sum_{m=1}^{\infty} e^{-(\beta m / R)^{2} D t} \\
& S_{d}(t)=\sum_{n=1}^{\infty} e^{-((2 n-1) \boldsymbol{r} / 2 \mathrm{~L}]^{2} D t}
\end{aligned}
$$

where the $\beta_{\mathrm{m}}$ are the zeroes of the zero-th order cylindrical Bessel function and are presented in Table A.1. 
Table A.1 Values of the parameters $\beta_{\mathrm{m}}$ for $\mathrm{m}=1$ to 20 .

These parameters satisfy the equation $\mathrm{J}_{0}\left(\beta_{\mathrm{m}}\right)=0$, with $\mathrm{J}_{0}(\mathrm{x})$ the zeroth order cylindrical Bessel function.

\begin{tabular}{rccc}
\hline $\mathrm{m}$ & $\beta_{\mathrm{m}}$ & $\mathrm{m}$ & $\beta_{\mathrm{m}}$ \\
\hline 1 & 2.4048255577 & 11 & 33.7758202136 \\
2 & 5.5200781103 & 12 & 36.9170983537 \\
3 & 8.6537279129 & 13 & 40.0584257646 \\
4 & 11.7915344391 & 14 & 43.1997917132 \\
5 & 14.9309177086 & 15 & 46.3411883717 \\
6 & 18.0710639679 & 16 & 49.4826098974 \\
7 & 21.2116366299 & 17 & 52.6240518411 \\
8 & 24.3524715308 & 18 & 55.7655107550 \\
9 & 27.4934791320 & 19 & 58.9069839261 \\
10 & 30.6346064684 & 20 & 62.0484691902 \\
& & & \\
\hline
\end{tabular}

Efficient means of calculating the infinite series in Eqns. (A.17 - A.20) have been developed [Pescatore, 1991] and will be implemented in the source term code.

\section{$\underline{\text { Rectangular Geometry }}$}

Given a rectangular-shaped, radioactive wasteform with dimensions $2 \mathrm{a}, 2 \mathrm{~b}$, and $2 \mathrm{c}$ along the $\mathrm{x}, \mathrm{y}$, and $\mathrm{z}$ directions, respectively, and given the same assumptions about the wasteform as were utilized earlier for the cylindrical case, the concentration of radioactive species in the rectangular block is as follows:

$$
C(x, y, z, t)=\frac{64}{\pi^{3}} C_{\mathrm{o}} e^{-\lambda t} T_{\mathrm{x}}(a, t) T_{\mathrm{y}}(b, t) T_{\mathrm{z}}(c, t)
$$

where the generic function $T_{u}(L, t)$ represents the open series:

$$
T_{u}(L, t)=\sum_{n=1}^{\infty}(-1)^{n+1} \cdot \frac{e^{-\left.|(2 n-1) \pi / 2 L|\right|^{2} D t}}{2 n-1} \cdot \cos \left(\frac{2 n-1}{2 L} \pi u\right)
$$


Equation (A.21) is obtained from the mathematically analogous expression for the temperature distribution within a heat-conducting parallelepiped.

Following [Pescatore, 1991], the release rate per unit area across the face $x=a$ of the wasteform is then:

$$
-\left.D \frac{\partial C}{\partial x}\right|_{\mathrm{x}=\mathrm{a}}=\frac{64}{\pi^{3}} C_{\mathrm{o}} D e^{-\lambda t} T_{\mathrm{y}}(b, t) T_{\mathrm{z}}(c, t)\left[\frac{\pi}{2 a} S_{\mathrm{d}}(a, t)\right]
$$

where the function $S_{d}(a, t)$ is the open series [A.20] with $L=a$. The total release rate, $Q_{a}$, across the face $x=a$ is obtained upon integration of Eqn. [A.23] over the entire area of this face, yielding:

$$
Q_{\mathrm{x}=\mathrm{a}}(\lambda ; t)=\frac{512}{\pi^{4}} C_{\mathrm{o}} D \frac{b c}{a} e^{-\lambda t} S_{\mathrm{p}}(b, t) S_{\mathrm{p}}(c, t) S_{\mathrm{d}}(a, t)
$$

where the functions $S_{p}(b, t)$ and $S_{p}(c, t)$ represent the open series (A.18) evaluated with $L=b$ and $\mathrm{L}=\mathrm{c}$, respectively. Analogous expressions for the total release rates from the other surfaces of the wasteforms can be obtained by substituting the dimensions of those surfaces in Eqn. (A.24).

\section{Dissolution Release}

The dissolution release model assumes that release occurs through a time-independent dissolution process. The flux of material released is evaluated using the expression:

$$
J_{\mathrm{dis}}=u C_{\mathrm{wf}}(0) e^{-\lambda t}\left(1-\frac{C_{\mathrm{s}}}{C_{\mathrm{sat}}}\right)
$$

where:

$$
\begin{aligned}
& \mathrm{u}=\text { dissolution velocity; } \\
& \mathrm{C}_{\mathrm{wr}}(0)= \text { initial concentration within the wasteform, it is evaluated } \\
& \text { by taking the initial mass of the wasteform, } \mathrm{M}_{\mathrm{wf}} \text {, and dividing } \\
& \text { by the wasteform volume, } \mathrm{V}_{\mathrm{wf}} ; \\
& \mathrm{C}_{\mathrm{s}}(\mathrm{t}) \quad \text { = solution concentration at time } \mathrm{t} ;
\end{aligned}
$$

and all other variables have been previously defined. 
The last expression in Eqn. (A.25) limits the release rate in case the solubility limit is approached.

The total release rate, $\mathrm{Q}$, from the waste form is:

$$
Q_{\mathrm{dis}}=J_{\mathrm{dis}} S=\left(\frac{u M_{\mathrm{wf}} S}{V_{\mathrm{wf}}}\right)\left(1-\frac{C_{\mathrm{s}}}{C_{\mathrm{sat}}}\right)
$$

where $\mathrm{S}$ is the surface area of the waste form.

\section{Influence of Localized Failure on Release}

If there is localized failure, the intact portion of the container still provides a barrier to release from the wasteform/container system. In this case, the release rates discussed above must be modified to take this into account.

As water enters through the breached area, it might be stored within the container until a bathtub forms and the height of the bathtub reaches the lowest region of failure. At this time, water would begin to flow out of the container. Accurately predicting the location of failures around a container is beyond the state-of-the-art and will not be attempted here. Instead, it will be assumed that, once a container is breached, there will be steady flow of water into and out of the container. The container flow rate will be the Darcy velocity multiplied by the ratio of the breached area to the total area.

The partially-failed container will be treated as a mixing bath in which radionuclides released from the wasteform are uniformly mixed within the container. The release rate from the container will be the product of the container flow rate and the container mixing bath concentration as calculated based on the various release mechanisms. This is identical to the approach used in the BLT computer code [Sullivan, 1989].

\section{Radionuclide Transport}

Migration of contaminants through the disposal facility will be modeled in one of two ways: the mixing cell cascade model or the finite difference solution of the advectiondispersion equation.

The mixing cell cascade approach is a generalization of the work performed by Sandia [Kozak, 1990] and relies on an analytical solution of the appropriate equations. With the analytical solution, the release rates from the disposal facility at any time are relatively easy 
to estimate. However, in order to obtain these solutions some restrictions on the generality of the problem must be made.

Both models begin with the advection-dispersion transport equation:

$$
\begin{aligned}
\frac{\partial}{\partial t}(\theta C) & =\frac{\partial}{\partial x} \theta D \frac{\partial c}{\partial x} V_{\mathrm{D}} C \\
& -\lambda(\theta C+\rho S)-\frac{\partial}{\partial t}(\rho S)
\end{aligned}
$$

$+q$

where:

$\mathrm{C} \quad=$ solution concentration;

$\theta \quad=$ the volumetric moisture content of the region (dimensionless);

$\mathrm{D}=$ the diffusion-dispersion coefficient,

$$
D=D_{\text {eff }}+\frac{a_{\mathrm{t}}\left|V_{\mathrm{d}}\right|}{\theta} ;
$$

$\mathrm{D}_{\mathrm{eff}}=$ effective diffusion coefficient;

$\mathrm{a}_{\mathrm{t}} \quad$ = transverse dispersivity;

$V_{\mathrm{d}} \quad=$ Darcy velocity;

$\lambda=$ radioactive decay constant;

$\mathrm{S} \quad=$ adsorbed concentration, the mass adsorbed per unit mass of the solid;

$\rho \quad=$ bulk density of the solid; and

$\mathrm{q}=$ source/sink term used to model release from the waste form.

In Eqn. (A.27) we assume that the mass adsorbed on the solid surfaces is in equilit,rium with the mass in solution. Further, we assume that this equilibrium can be described using a concentration independent partition coefficient, $\mathrm{K}_{\mathrm{d}}$, as follows:

$$
S=K_{\mathrm{d}} C
$$


Using the above relationship for $S$, assuming that the bulk density remains constant within the disposal facility and rearranging Eqn. (A.27), the following equation is obtained:

$$
\begin{aligned}
\frac{\partial}{\partial t}(R \theta C) & =\frac{\partial}{\partial x}\left(\theta D \frac{\partial C}{\partial x}\right)-\frac{\partial}{\partial x}\left(V_{\mathrm{D}} C\right) \\
& -\lambda \theta R C+q
\end{aligned}
$$

where:

$$
R=1+\frac{\rho K d}{\theta}
$$

$\mathrm{R}$ is kno:, 3 as the retardation coefficient.

\section{Mixing-Cell Cascade}

The mixing cell cascade model divides the disposal facility into a number of uniform size mixing cells as depicted in Figure A.2. Within each cell it is assumed that the contaminant released from the waste form is uniformly mixed thereby giving a uniform solution concentration. In order to obtain an analytical solution the following assumptions are made:

a) Migration is dominated by advective flow and therefore diffusion and dispersion can be ignored.

b) The advection velocity, moisture content, and the retardation coefficient are constant throughout the disposal facility. Although these parameters will show variations due to different materials in the facility, they should be a selected to provide a representative average for the entire facility.

Using these assumptions in Eqn. (A.29) the transport equation for the $\mathrm{i}^{\text {th }}$ mixing cell becomes:

$$
\frac{\partial C_{\mathrm{i}}}{\partial t}=-\frac{V_{\mathrm{D}}}{\theta R} \frac{\partial C_{\mathrm{i}}}{\partial x}-\lambda C_{\mathrm{i}}+\frac{q_{\mathrm{i}}}{\theta R}
$$



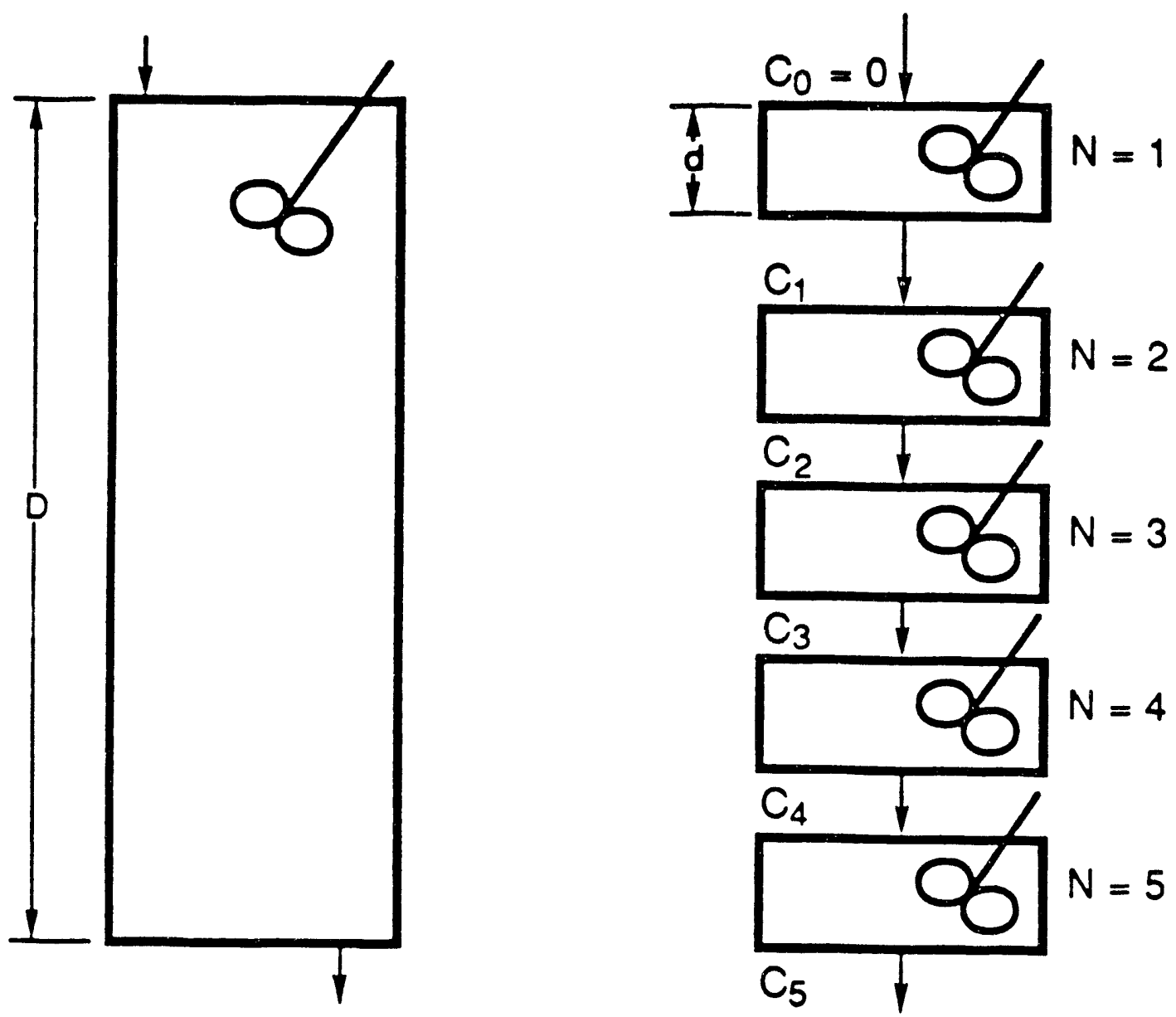

Figure A.2 Schematic representation of the mixing cell cascade approach. (a) a single mixing cell, (b) multiple mixing cells. [From Kozak, 1990] 
where the subscript $\mathrm{i}$ refers to the $\mathrm{i}^{\text {th }}$ mixing cell.

For a disposal facility of height $\mathrm{H}$, there are $\mathrm{N}$ mixing cells of height $\mathrm{h}(\mathrm{h}=\mathrm{H} / \mathrm{N})$. Using this definition of the size of the mixing cell and upwind differencing (because migration is assumed to be controlled by advection) to estimate the spatial derivative, Eqn. (A.31) becomes:

$$
\frac{d C_{\mathrm{i}}}{d t}=-\alpha N\left(C_{\mathrm{i}}-C_{\mathrm{i}-1}\right)-\lambda C_{\mathrm{i}}+\beta N Q_{\mathrm{i}}
$$

where:

$\mathrm{Q}=$ the total release rate from the wasteform;

$\alpha=\mathrm{V}_{\mathrm{d}} /(\theta \mathrm{RH})$;

$\beta=1 /\left(\theta \mathrm{RHA}_{\mathrm{f}}\right) ;$ and

$A_{f}=$ the area of the facility.

In this description, $\mathrm{HA}_{\mathrm{f}} / \mathrm{N}$ is the volume of a single mixing cell.

Equation (A.32) applies to each mixing cell. For the first cell, $\mathrm{C}_{\mathrm{i}-1}$ is set to zero. This is equivalent to assuming that no contaminant enters through the top of the facility. Therefore, we have a system of $\mathrm{N}$ coupled linear differential equations. This system of equations has been solved to provide an analytical solution for arbitrary wasteform sources, $q_{1}$, within each mixing cell.

The resulting expression for the concentration in the $\mathrm{N}^{\text {th }}$ mixing cell is:

$$
\begin{aligned}
C_{N}(t) & =e^{-\lambda t} e^{-\alpha N t} \sum_{n=0}^{N-1} \frac{(\alpha N t)^{n}}{n !} C_{N-n}(0) \\
& +\beta N e^{-\lambda t} e^{-\alpha N i} \sum_{n=0}^{N-1}(\alpha N)^{n} I_{n+1}
\end{aligned}
$$


where:

$$
I_{\mathrm{n}+1}=\int_{t_{0}}^{t} d t_{1} \int_{0}^{t_{1}} d t_{2} \int_{0}^{\mathrm{t}_{2}} \cdots \int_{0}^{t_{\mathrm{n}}} d t_{\mathrm{n}+1} \quad Q_{N-\mathrm{n}}(t) e^{(\alpha N+\lambda) \mathrm{t}}
$$

Equation (A.34) applies only if the parameter alpha is constant.

The first term in Eqn. (A.33) arises from the initial conditions, $\left(C_{n}(0)\right.$ is the concentration in the $\mathrm{n}^{\text {th }}$ cell at time $=0$ ). In most instances, the initial concentration in the solute is expected to be zero.

The integral in Eqn. (A.34) can be evaluated analytically for certain functional forms of the wasteform release rate term, $Q_{n}$. In particular, rinse release with partitioning and dissolution release (constant release rate) with radioactive decay can be modeled as follows:

$$
\begin{aligned}
Q_{\mathrm{n}}(t) & =C_{\mathrm{n}}\left(\tau_{\mathrm{n}, \mathrm{b}}\right) \delta\left(t-\tau_{\mathrm{n}, \mathrm{b}}\right) \\
& +Q_{\mathrm{n}}(0) e^{-\lambda t}\left[H\left(t-\tau_{\mathrm{n}, \mathrm{b}}\right)-H\left(t-\tau_{\mathrm{n}, \mathrm{f}}\right)\right]
\end{aligned}
$$

where:

$$
C_{\mathrm{n}}\left(\tau_{\mathrm{n}, \mathrm{b}}\right)=\frac{M_{\mathrm{r}, \mathrm{n}} e^{-\lambda \tau_{\mathrm{n}, \mathrm{o}}}}{\theta V_{\mathrm{n}} R}
$$

where:

$$
\begin{aligned}
& \mathrm{M}_{\mathrm{r}, \mathrm{n}} \quad \text { = the mass available for rinse release at } \mathrm{t}=0 \text {; } \\
& \tau_{\mathrm{n}, \mathrm{b}} \quad=\text { time of total failure of the } \mathrm{n}^{\text {th }} \text { container; } \\
& V_{n}=\text { the volume of the } n^{\text {th }} \text { mixing cell (the volume of the entire } \\
& \text { disposal facility divided by the number of } \pi \text { xing cells, } N \text { ); } \\
& \delta\left(\mathrm{t}-\tau_{\mathrm{n} . \mathrm{b}}\right)=\text { Dirac } \delta \text { function; } \\
& \mathrm{Q}_{\mathrm{n}}(0) \quad=\text { release rate at time }=0 \text {; } \\
& \mathrm{H}\left(\mathrm{t}-\tau_{\mathrm{n}, \mathrm{b}}\right)=\text { Heaviside function, defined as follows: } \\
& \begin{array}{ll}
H\left(t-\tau_{n . b}\right)=0 & t<\tau_{n, b} \\
H\left(t-T_{n . b}\right)=1 & t>\tau_{n, b}
\end{array}
\end{aligned}
$$


$\tau_{\text {n.f }}=$ time of total wasteform dissolution, i.e., no further release is permitted after this time. This can be estimated by dividing the initial inventory of the wasteform by the initial release rate and adding this value to the time of breach.

The first term represents the instantaneous surface wash-off that occurs immediately after container breach when water first contacts the wasteform. The second term models a constant release rate corrected for first order (radioactive) decay which starts immediately after container breach and finishes at the time the entire inventory is released. This is similar to the wasteform dissolution model.

If $Q_{n}(0)$ is used to mudel a dissolution controlled process, it would be estimated as the product of the dissolution velocity, surface area of the wasteform, and the concentration of contaminant within the wasteform as discussed in the wasteform release section of this Appendix.

As currently written, the release rate term, $Q_{n}$, is not directly applicable to modeling the monotonically decreasing release rate representative of diffusion. Including a diffusion term is conceptually easy. However, because the analytical solution to diffusion release is an infinite series (see the diffusion release section in this Appendix), the multiple integrations required in Eqn. (A.37) are cumbersome. Considerction is being given to the inclusion of a diffusion term in the expression for the release rate term, $Q_{n}$.

However, if the exponentially decaying release rate term is used to approximate release that is controlled by diffusion, $Q_{n}(0)$ would be estimated as the product of the diffusion cosfficient, a geometric factor which involves the surface area, and the concentration in the wasteform.

Using the wasteform release rate term given in Eqn. (A.35) in the analytical solution, Г.qn. (A.33), yields the following solution for the concentration in the last mixing cell: 


$$
\begin{aligned}
& C_{N(i)}=e^{-\lambda t} e^{-\alpha N t} \sum_{n=0}^{N-1} C_{N-n}(0)(\alpha N t)^{n} / n ! \\
& +\sum_{n=0}^{N-1} C_{N-n}\left(\tau_{N-n, b}\right) H\left(t-\tau_{N-n, b}\right)\left(\alpha N\left(t-\tau_{N-n, b}\right)\right)^{n} \cdot e^{-(\alpha N+\lambda)\left(t-\tau_{n-n, b}\right)} / n ! \\
& +\frac{\beta}{\alpha} e^{-\lambda t} \sum_{n=0}^{N-1} Q_{Y-n}(0) H\left(t-\tau_{Y-n, b}\right)\left(1-e^{-\alpha N\left(t-\tau_{n-, b}\right)}\right) \\
& -\frac{\beta}{\alpha} e^{-\lambda t} \sum_{n=1}^{N-1} Q_{n-n}(0) H\left(t-\tau_{N-n, b}\right) e^{-\alpha N\left(t-\tau_{n, n, b}\right)} \sum_{i=1}^{n} \frac{(\alpha N)^{i}\left(t-\tau_{N-n, b}\right)^{i}}{i !} \\
& -\frac{\beta}{\alpha} e^{-\lambda t} \sum_{n=0}^{N-1} Q_{N-n}(0) H\left(t-\tau_{N-n, f}\right)\left(1-e^{-\alpha N\left(t-\tau_{n,-,}\right)}\right) \\
& +\frac{\beta}{\alpha} e^{\lambda t} \sum_{n=1}^{i-1} Q_{X-n}(0) H\left(t-\tau_{N-n . f}\right) e^{-\alpha \times\left(t-\tau_{n-, f}\right)} \sum_{i=1}^{n} \frac{\left(\alpha N\left(t-\tau_{N-n, f}\right)\right)^{i}}{i !}
\end{aligned}
$$

The above expression for $C_{n}$ is quite general and permits each mixing cell to model a container with a unique time of breach, inventory, and release rate. The first term in Eqn. (A.37) represents the initial condition. The second term represents the concentration in solution due to surface rinse with partitioning beginning immediately after breach. The remaining four terms represent the concentration of radioactivity in solution due to a wasteform that releases mass uniformly in time adjusted for radinactive decay.

A number of different situations can be adequately modeled with Eqn. (A.37) through proper selection of the input parameters. However, because of the restriction that the wasteform release rate be expressed either by surface rinse or an exponentially decaying rate, the above expression can not be used to investigate localized failures because they lead to time-dependent wasteform release rates (as the failure area grows, the release rate increases).

The mass flux out of the disposal facility is the concentration in the last cell multiplied by the Darcy velocity. The total mass flow rate is the mass flux multiplied by the area of the disposal facility. 


$$
M_{\mathrm{f}}(t)=C_{\mathrm{n}}(t) V_{\mathrm{d}} A_{\mathrm{f}}
$$

\section{Finite Difference Solution Procedure}

If the assumptions of the mixing cell cascade model (constant water flow, uniform retardation and moisture content, advection controlled transport, and only catastrophic container failures (e.g., no localized failures)) are not justified, the finite difference solution procedure is recommended.

The finite difference procedure begins with Eqn. (A.29). The second order derivative (the diffusion-dispersion term) will be estimated using centered differences. The first order spatial derivative will be approximated using upwind differencing. The time derivative term will be approximated using a first order backward difference. Performing this resuls in the following equation:

$$
\begin{aligned}
\frac{\left(\theta R C_{n}\right)^{1+1}}{\Delta t} & =\frac{\left(\theta R C_{n}\right)^{\prime}}{\Delta t} \\
& +C_{n+1}^{i+1}\left[\frac{(\theta D)_{n+1}^{i-1}}{\left.\Delta X_{n} \Delta X_{n . a}\right]}\right. \\
& -C_{n}^{i-1}\left[\frac{(\theta D)_{n}^{i+1}}{\Delta X_{n} \Delta X_{n . a}^{i}}+\frac{(\theta D)_{n}^{i+1}}{\Delta X_{n-1}^{i} \Delta X_{n . a}}+\frac{V_{D}^{i+1}}{\Delta X_{n-1}}+\lambda(\theta R)^{i+1}\right] \\
& +C_{n-1}^{i+1}\left[\frac{(\theta D)_{n-1}^{i-1}}{\Delta X_{n-1} \Delta X_{n . a}}+\frac{V_{D}^{i+1}}{\Delta X_{n-1}}\right] \\
& +q_{n}^{i+1}
\end{aligned}
$$


where $\Delta X_{n . a}=\frac{1}{2}\left(\Delta Y_{n}+\Delta X_{n-1}\right)$

where the superscript $\mathrm{i}$ refers to the time level of the calculation and the subscript $\mathrm{n}$ refers to the spatial location of the calculation. Except for the time-derivative term, all concentrations are evaluated at the new time level, $\mathrm{i}+1$. This is known as the implicit solution procedure and insures that the numerical solution is stable, i.e. numerical errors that occur in solving the equation are damped.

Equation (A.39) applies for each finite difference node in the interior ( $\mathrm{n}$ not equal to 1 or $\mathrm{N}$ ) of the domain being simulated. Equation (A.39) illustrates that the concentration at node $n$ is a function of its two nearest neighbors. The system of equations which accounts for the concentration at each point can be rearranged such that all unknown variables at the new time level are on the left hand side of the equation and all known variables (the release rate and concentrations at the old time level) are on the right hand side. Performing this arrangement and using matrix notation yields:

$$
\bar{A} \bar{C}(i+1)=\bar{S}
$$

where $\mathrm{A}$ is a tridiagonal matrix comprised of the terms that multiply the concentrations at each node at time leve! $\mathrm{i}+1, \mathrm{C}$ is a vector that represents the concentration at each node at time level $i+1$, and $S$ is a source term comprised of the release rate from the wasteform over the time step plus the concentration at time level $i$. The system of equations represented by Eqn. (A.40) can be solved quite easily using standard numerical techniques.

Special consideration is given to the first and last node. These nodes are modified to reflect the boundary conditions imposed on the problem. Typical boundary conditions are that the concentration or the flux is specified as a function of time. The boundary condition applied to the top of the disposal facility could be zero mass flux entering the facility. At the bottom of the facility, the concentration or the flux may be specified. Requiring the concentration at the bottom of the facility to be zero would lead to the highest mass flux out of the repository. Similarly, requiring zero mass flux out would lead to the highest solution concentration.

A detailed description of the implementation of the boundary conditions and the resulting matrix equations will be supplied with the code documentation provided with the final product of this project. 


\section{REFERENCES}

[Gerhold, 1981]

W.F. Gerhold, E. Escalante, and B.T. Sanderson, "The Corrosion Behavior of Selected Stainless Steels in Soil Environments," NBSIR 81-2228, National Bureau of Standards, 1981.

[Kozak, 1990]

M.W. Kozak, et. al., Background Information for the Development of a Low-Level Waste Performance Assessment Methodology: Computer Code Implementation and Assessment," NUREG/CR-5453, SAND89-2509, Volume 5, Sandia National Laboratories, 1990.

[Mughabghab, 1989]

S.F. Mughabghab and T.M. Sullivan, "Evaluation of the Pitting Corrosion of Carbon Steels and Other Ferrous Metals in Soil Systems," Waste Management, Vol. 9, pp. 239-251, 1989.

[Pescatore, 1991]

C. Pescatore, "Leach Rate Expressions for Performance Assessment of Solidified, Low-Level Radioactive Waste," accepted for publication by the Journal of Waste Management, also available as an informal report, WM-3276-12, Brookhaven National Laboratory, December, 1990.

[Romanoff, 1957]

M. Romanoff, "Underground Corrosion," National Bureau of Standards Circular 579, 1957.

[Sullivan, 1989]

T M. Sullivan and C.J. Suen, "Low-Level Waste Shallow Land Disposal Source Term Model: Data Input Guides," NUREG/CR-5387, BNL-NUREG-52206, U.S. Nuclear Regulatory Commission, 1989.

[Sullivan, 1991]

T.M. Sullivan and C.J. Suen, "Low-Level Waste Source Term Model Development and Testing," in press, U.S. Nuclear Regulatory Commission, 1991. 
Selection of Models to Calculate the LLW Source Term

TH DATE REPORT PUBLISTED

\begin{tabular}{|r|r}
\hline OATE REPORT PUBLISHED \\
\hline MONTH & 1991
\end{tabular}

4 FIN OR GRANT NUMBER L1409

5. AUTHORS:

T. M. Sulivan

Formal

Brookhaven National Laboratory

Upton, New York 11973

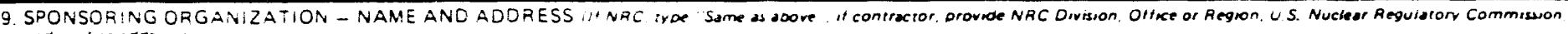
and masing sodress:

Division of Low Level Waste Management and Decommissioning

office of Nuclear Material Safety and Safeguards

L.S. Nuclear Regulatory Commission

Washington, DC 20555

10. SUPPLEMENTARY NOTES

11. ABSTRACT 200 wores or less:

Performance assessment of a LLW disposal facility begins with an estimation of the rate at which radionuclides migrate out of the facility (i.e., source term). The focus of his work is to develop a methodology for calculating the source term. In general, the source term is influenced by the radionuclide inventory, the wasteforms and containers used to dispose of the inventory, and the physical processes that lead to release from the facility (fluid flow, container degradation, wasteform leaching, and radionuclide transport). In turn, many of these physical processes are influenced by the design of the disposal facility (e.g., infiltration of water). The complexity of the problem and the absence of appropriate data prevent development of an entirely mechanistic representation of radionuclide release from a disposal facility. Typically, a number of assumptions, based on knowledge of the disposal system, are used to simplify the problem. This document provides a brief overview of disposal practices and reviews existing source term models as background for selecting appropriate models for estimating the source term. The selection rationale and the mathematical details of the models are presented. Finally, guidance is presented for combining the inventory data with appropriate mechanisms describing release from the disposal facility.

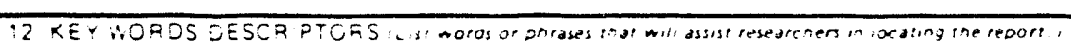

Low-Level Radioactive Wastes, Waste Facilities and Disposal Methods, Radioactive Waste Facilities Source Terms, Calculation Methods, Performance Testing, Mathematical. Models, Container Degradation, Wasteform Leaching, Radionuclide Migration, Radioactive Effluents, Dose Rates

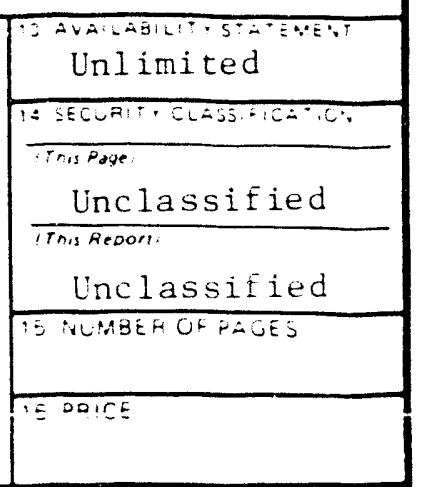



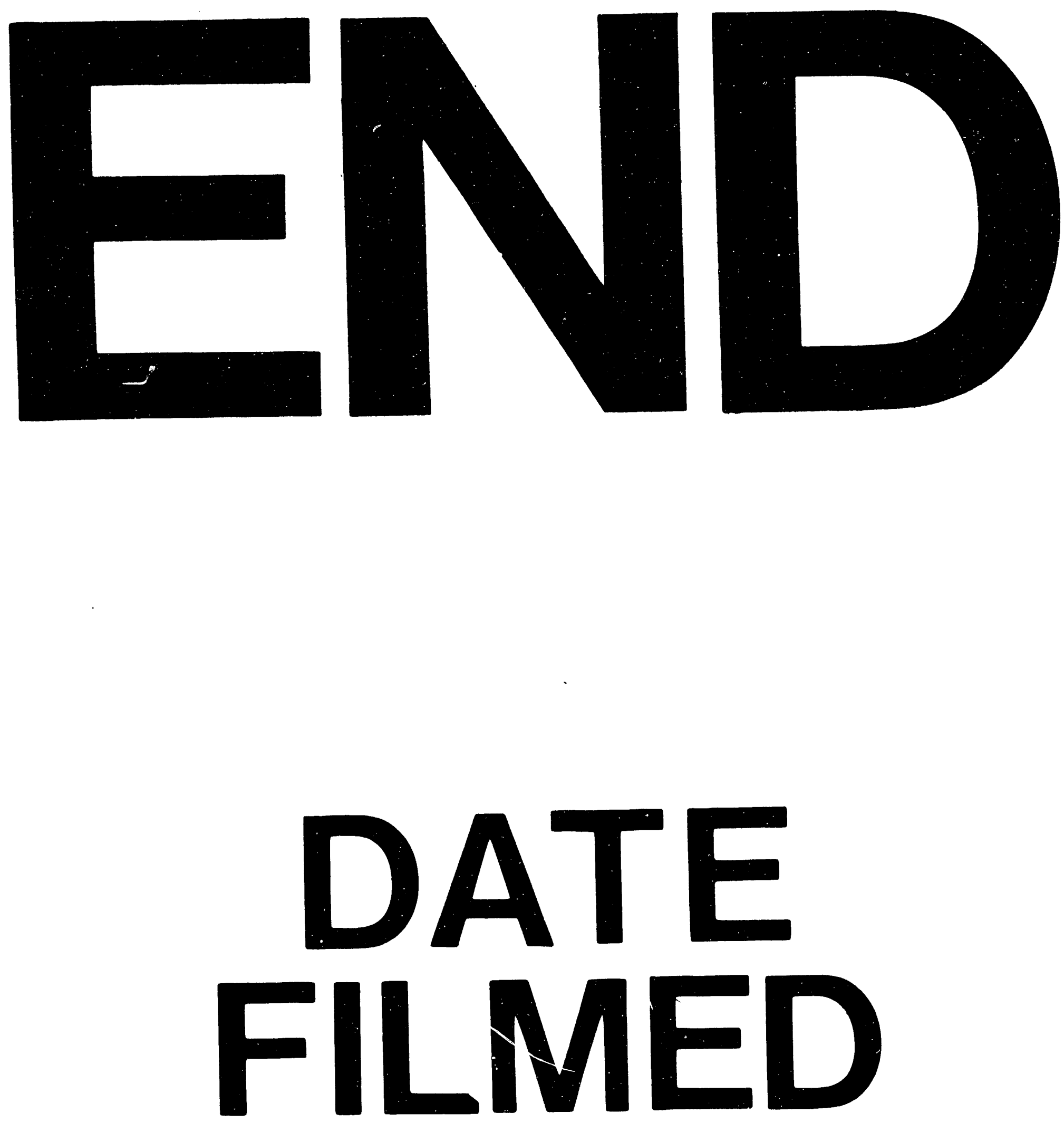

$\pm$

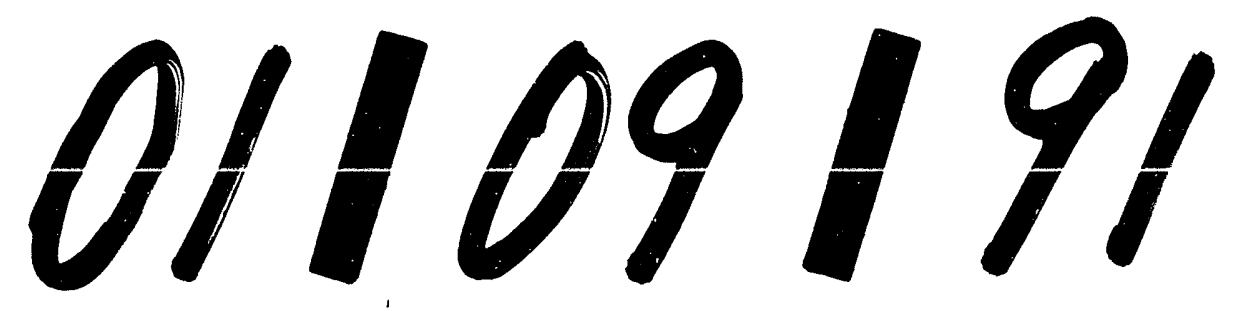

$-$ 


$$
\ldots
$$

